\title{
QTL mapping for soybean (Glycine max L.) leaf chlorophyll-content traits in a genotyped RIL population by using RAD- seq based high-density linkage map
}

Liang Wang ${ }^{1,2,3,4}$, Brima Conteh ${ }^{1,2,3}$, Linzhi Fang ${ }^{1,2,3}$, Qiuju Xia ${ }^{5}$ and Hai Nian ${ }^{1,2,3^{*}}$ (D)

\begin{abstract}
Background: Different soybean (Glycine max L.) leaf chlorophyll-content traits are considered to be significantly linked to soybean yield. To map the quantitative trait loci (QTLs) of soybean leaf chlorophyll-content traits, an advanced recombinant inbred line (RIL, ZH, Zhonghuang $24 \times$ Huaxia 3) population was adopted to phenotypic data acquisitions for the target traits across six distinct environments (seasons and soybean growth stages). Moreover, the restriction site-associated DNA sequencing (RAD-seq) based high-density genetic linkage map of the RIL population was utilized for QTL mapping by carrying out the composite interval mapping (CIM) approach.

Results: Correlation analyses showed that most traits were correlated with each other under specific chlorophyll assessing method and were regulated both by hereditary and environmental factors. In this study, 78 QTLs for soybean leaf chlorophyll-content traits were identified. Furthermore, 13 major QTLs and five important QTL hotspots were classified and highlighted from the detected QTLs. Finally, Glyma01g15506, Glyma02g08910, Glyma02g11110, Glyma07g15960, Glyma15g19670 and Glyma15g19810 were predicted from the genetic intervals of the major QTLs and important QTL hotspots.

Conclusions: The detected QTLs and candidate genes may facilitate to gain a better understanding of the hereditary basis of soybean leaf chlorophyll-content traits and may be valuable to pave the way for the markerassisted selection (MAS) breeding of the target traits.
\end{abstract}

Keywords: Soybean, Leaf chlorophyll-content traits, QTL mapping

\footnotetext{
* Correspondence: hnian@scau.edu.cn

${ }^{1}$ The State Key Laboratory for Conservation and Utilization of Subtropical Agro-bioresources, South China Agricultural University, Guangzhou 510642, Guangdong, People's Republic of China

${ }^{2}$ The Key Laboratory of Plant Molecular Breeding of Guangdong Province, College of Agriculture, South China Agricultural University, Guangzhou 510642, Guangdong, People's Republic of China

Full list of author information is available at the end of the article
}

(c) The Author(s). 2020 Open Access This article is licensed under a Creative Commons Attribution 4.0 International License, which permits use, sharing, adaptation, distribution and reproduction in any medium or format, as long as you give appropriate credit to the original author(s) and the source, provide a link to the Creative Commons licence, and indicate if changes were made. The images or other third party material in this article are included in the article's Creative Commons licence, unless indicated otherwise in a credit line to the material. If material is not included in the article's Creative Commons licence and your intended use is not permitted by statutory regulation or exceeds the permitted use, you will need to obtain permission directly from the copyright holder. To view a copy of this licence, visit http://creativecommons.org/licenses/by/4.0/ The Creative Commons Public Domain Dedication waiver (http://creativecommons.org/publicdomain/zero/1.0/) applies to the data made available in this article, unless otherwise stated in a credit line to the data. 


\section{Background}

Leaf chlorophylls are the major components in chloroplasts that affect photosynthetic capacities. The leaf chlorophylls were usually evaluated by using the extracted-based methods and can also be assessed by non-destructive approaches [1, 2]. Quantification by extract-based methods often involved the collections of leaf samples, solvent-based pigment extractions, and measurements of different chlorophylls (mainly chlorophyll a and chlorophyll b) by spectrophotometry [2-4]. Compared to the extraction methods, the soil plant analysis development (SPAD) assessing method by a handheld SPAD chlorophyll meter is non-destructive, fast and cheap for relative chlorophylls assessments [5]. Early studies have turned out that the soybean (Glycine max L.) leaf chlorophyll contents were positively correlated to seed yield during soybean reproductive stages [6, 7]. Hence, a better understanding of the genetic basis of chlorophyll-content traits in soybean leaves may be valuable for accelerating the soybean high-yield breeding.

Soybean leaf chlorophyll-contents were complex quantity traits controlled by polygenes that difficult to identify the major quantitative trait loci (QTLs) or functional genes [8]. Recently, the bottlenecks of traditional QTL mapping markers, like low genome coverage and uneven distributions, have been overcome by the rise of single nucleotide polymorphism (SNP) markers [9, 10]. Based on their genome-wide stability and abundance, SNP markers revolutionarily affected the high-density genetic map constructions and were adopted for seeking detailed hereditary information $[11,12]$. To match with the massive DNA sequencing platforms, whole-genome sequencing (WGS) strategies have become the popular choices for next-generation sequencing (NGS) and were universally applied in SNP discovering and large population genotyping $[13,14]$. These approaches mainly include resequencing, genotyping by sequencing (GBS) [15], specific length amplified fragment sequencing (SLAF-seq) [16], restriction site-associated DNA tag sequencing (RAD-seq) [17], and 2b-RAD [18]. The NGS technologies have been widely adopted in soybean, rice, wheat, sunflower and other crops [19-23]. Notably, QTL mapping by using soybean recombinant inbred line (RIL) populations and their RAD-seq based recombination bin marker genetic maps were reported to identify important soybean traits QTLs in recent years [24, 25]. Besides, the genome-wide association study (GWAS) was another primary mapping approach that relied on linkage disequilibrium genotyping arrays and investigated the associations of the SNPs throughout the entire genomes [26].

To date, there were 18 bi-parental and 6 GWAS QTLs for soybean leaf SPAD on SoyBase (https://www.soybase. org/) throughout different genetic backgrounds, sampling locations and mapping strategies. In another study, Dhanapal et al. collected 332 soybean varieties and assessed the chlorophyll a (eChl_A), chlorophyll b (eChl_ B) and chlorophyll a/b ratio (eChl_R) in the soybean leaf extracts [2]. By carrying out the GWAS method, 14, 7 and 10 QTLs were identified for eChl_A, eChl_B and eChl_R, respectively [2]. In general, the QTLs for soybean leaf chlorophyll-content traits are still lacking compared to other soybean traits. Moreover, due to technical limitations, most bi-parental QTLs were detected by the traditional molecular markers and relatively low-density genetic maps.

In this study, we took the SPAD values as the indicators of the relative soybean leaf chlorophyll contents. These values were collected from the top, middle and bottom leaf sampling sites of the target soybean plants (TSP, top leaves SPAD value; MSP, mid leaves SPAD value; $B S P$, bottom leaves SPAD value). The average SPAD value (ASP) was the mean of TSP, MSP and BSP. Furthermore, based on spectrophotometer assessing of the top site sampled-leaf extracts, we quantified the target leaf chlorophylls a and b (Chl_A and Chl_B) contents and obtained the ratios of chlorophyll $a$ to $b$ (chlorophyll A/B ratios, Chl_A/B). For the assessments of these target soybean leaf chlorophyll-content traits, an advanced soybean RIL population (ZH RIL population) was adopted for the phenotypic data acquisitions. And the ZH RIL population was originated from the hybridization between 'ZhongHuang 24' (maternal plant) and 'Huaxia 3' (paternal plant) by using a single seed descent (SSD) method derived from individual $\mathrm{F}_{2}$ plants [27]. 'Zhonghuang 24' is a variety from the Institute of Crop Sciences, Chinese Academy of Agricultural Sciences, which adapts to the Huang-Huai-Hai growing region. 'Huaxia 3' is a high-yield soybean cultivar from South China Agricultural University. Previously, Liu et al. well-genotyped this RIL population and constructed a high-density bin marker map for the population with the RAD-seq approach [24]. Importantly, based on the yield difference between the parent soybeans of the RIL population, they finely mapped diverse QTLs for different soybean yield-related traits [24]. In the current investigation, we consecutively collected the phenotypic data of the chlorophyll-content traits across different seasons and soybean reproductive growth stages. By using the identical RIL population and its RAD-seq based high-density bin marker map, we identified 78 QTLs for the target traits. Concomitantly, we explored the relations between the QTLs identified in the present research and the published QTLs in the previous studies covering soybean leaf chlorophyll-content traits as well as soybean yield-related traits. Finally, we predicted six candidate genes for the target soybean leaf chlorophyll-content traits. In summary, the findings in 
the current study may provide clues for future gene functional research on soybean leaf chlorophyll-content traits and may be useful for promoting MAS (markassisted selection) breeding of high-yield soybean varieties.

\section{Results}

\section{Phenotypic analyses of soybean leaf content traits with} two distinct assessing methods

In previous studies, soybean leaf chlorophyll contents were reported to be positively correlated to seed yield during reproductive stages $[6,7]$. Soybean leaf chlorophyll contents are complicated quantitative traits, which could be determined by different environmental and hereditary factors, such as, temperature and diverse growth stages of the RILs. To better map distinct QTLs for soybean leaf chlorophyll-content traits in the ZH RIL population, the phenotypic data and soybean leaf samples were collected at 9 a. m. according to the R1, R4 and R6 growth stages of different soybean lines across the spring and summer of 2017. Phenotypic data of TSP, MSP, BSP and ASP were collected across seasons and soybean growth stages. And Chl_A, Chl_B and Chl_A/B were phenotyped at different soybean growth stages. Most target traits of 'Zhonghuang 24' (maternal parent) presented higher values than those of 'Huaxia 3' (paternal parent), providing ideal materials for QTL mapping analyses. Generally, the phenotypic data of the RILs showed wide spans and displayed continuous distributions. Phenotypic frequency distributions of the target traits in the ZH RILs were depicted in Figs. 1 and 2. As is shown in the figures, the segregations of the chlorophyll-content traits fit normal or skew-normal distribution models, with typical quantitative genetic characteristics. Furthermore, the skewness and kurtosis of the distributions were listed in Table 1. Importantly, for each soybean leaf chlorophyll-content trait, the transgressive segregations widely presented in the RILs suggesting that the positive or negative alleles existed in the parent soybeans. Correlation analyses of the phenotypic data in RILs turned out that most chlorophyll-content traits were strongly correlated under the specific testing method (SPAD testing or spectrophotometer assessing of leaf extracts) and showed statistically significant $(P<$ 0.01) (Additional file 1: Table S1). Interestingly, the SPAD values (TSP, BSP, MSP, and ASP) did not show significant correlations with Chl_A, Chl_B, or Chl_A/B in the current study. Overall, ASP presented the highest positive correlation coefficients to other SPAD traits. And Chl_A exhibited the strongest positive correlations to Chl_B and Chl_A/B. The Chl_A/B values were derived from the ratios Chl_A to Chl_B, which showed broadly positive correlations to Chl_A and negative correlations to Chl_B (with an exception of the R1 growth stage in the summer of 2017). Besides, we analyzed the phenotypic data correlations in different environments (Additional file 1: Table S2). As a result, the phenotypic data at the R6 growth stages in the spring and the summer of 2017 presented relatively better correlations with other circumstances.

\section{Mapping for the chlorophyll-content QTLs by using a genotyped high-density bin marker linkage map}

The 47,472 high confidence polymorphic SNP sites were genotyped in the ZH RILs (Additional file 2: Fig. S1) and all the sites were then integrated as the recombination bin markers [24]. The SNP numbers in every bin marker on different chromosomes were listed in Table S3 (Additional file 1). And 2639 recombinant bin markers were acquired (Additional file 1: Table S4 and Additional file 3: Fig. S2). The bin physical length spanned from 20.01 kilobytes $(\mathrm{kb})$ to 17.43 megabytes $(\mathrm{Mb})$ with an average length of $360.01 \mathrm{~kb}$. A high-density bin linkage map was constructed (Fig. 3), with an average distance of $1.00 \mathrm{cM}$ between adjacent markers, covering 2638.24 cM in the Glyma.Wm82. a1. v1.1 reference genome. Chi-square test of the 2639 bin markers turned out that 2356 markers $(89.28 \%$ of the total bin markers) displayed between parents with 1:1 segregation $(P>0.05)$, which was consistent with the characteristics of monogenic markers (Additional file 1: Table S5). Besides, 283 bin markers (account for 10.72\%) exhibited separation distortion $(P<0.05)$. Most bin markers tended to be homozygous, and the heterozygous rate of bin markers was less than $4.79 \%$ (Additional file 1: Table S5).

By carrying out the composite interval mapping (CIM) method, 78 chlorophyll-content QTLs were identified distributing on the 19 soybean chromosomes (except for chromosome 20) (Additional file 1: Table S6). The phenotypic variations of the detected QTLs ranged from $5.10 \%$ ( $\left.q C h l_{-} B 2 f\right)$ to $16.55 \%$ ( $\left.q A S P 1 b-1\right)$. There were 59 SPAD QTLs widely distributed on the 18 soybean chromosomes (except for chromosomes 12 and 20). Among these QTLs, 14, 18, 11 and 16 QTLs were mapped for TSP, MSP, BSP and ASP, respectively. $q T S P 1 b$ and $q T S P 2 e$ were the two dominant effect QTLs $\left(R^{2}=11.97\right.$ and $10.08 \%$ ) for TSP. $q T S P 1 b$ was identified by the bin46 marker on chromosome 01 and qTSP2e was detected by the bin30 marker on chromosome 02 . Interestingly, $q A S P 1 b-1$ was also mapped by the bin 46 marker on chromosome 01 and exhibited the highest phenotypic variance $\left(R^{2}=16.55 \%\right)$ among the identified QTLs. Besides, $q A S P 5 d-2$ and $q A S P 15 a\left(R^{2}=12.05\right.$ and $11.94 \%)$ were designated as the other two major QTLs $\left(R^{2}>10 \%\right)$ for ASP. Coincidentally, qMSP15a-1 fell in the identical physical interval with $q A S P 15 a$ and was one dominant effect QTL for MSP. Furthermore, $q M S P 3 e$ and $q M S P 19 f$ were the other two major MSP 


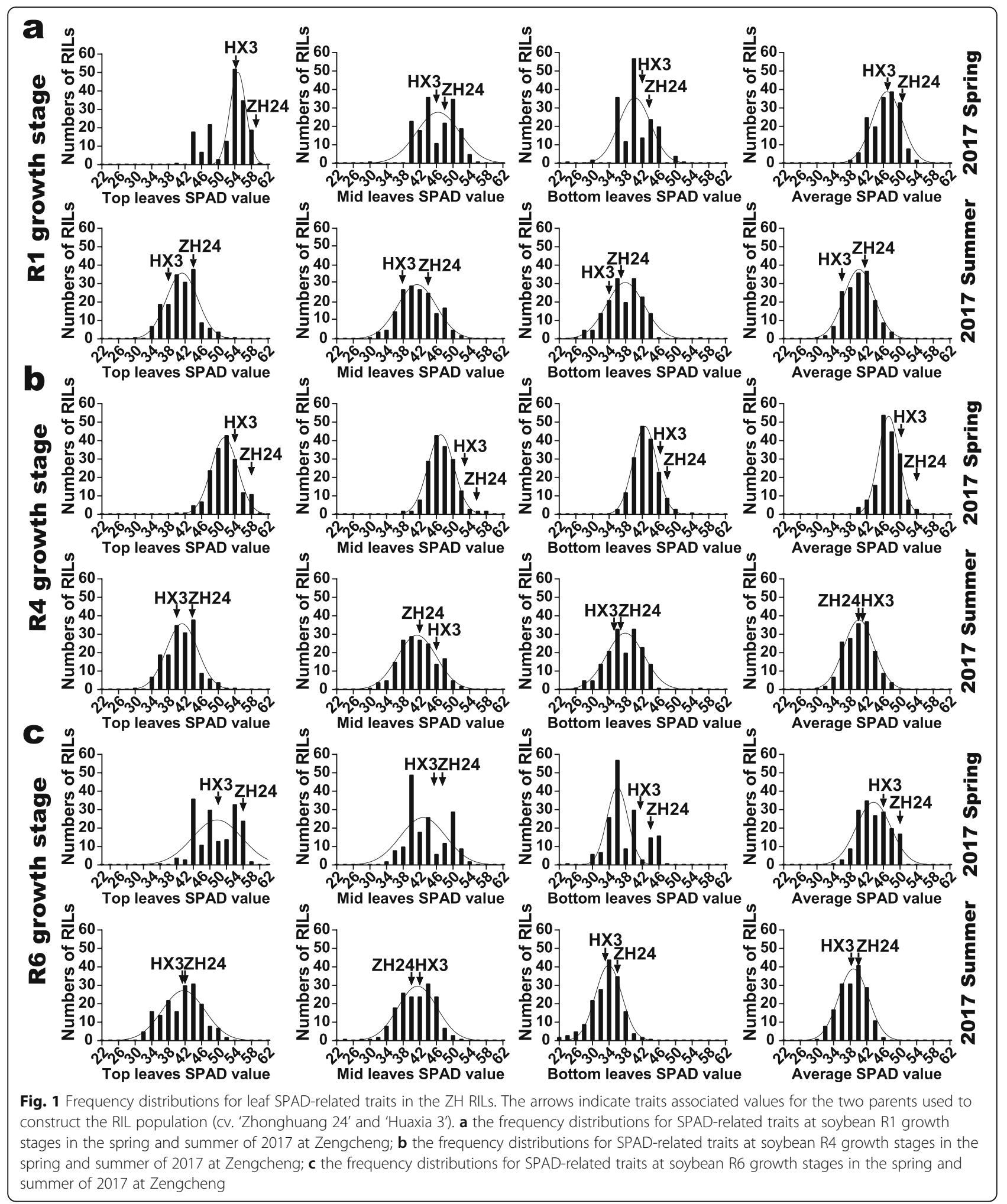

QTLs on chromosomes 03 and $15\left(R^{2}=10.06\right.$ and $15.50 \%)$. And $q B S P 9 e$ was the only major QTL for BSP. In contrast, 19 extracting chlorophyll content QTLs were identified and distributed on the 12 soybean chromosomes with phenotypic variances spanned from $5.10 \%\left(q C h l \_B 2 f\right)$ to $13.55 \%$ ( $\left.q C h l \_A 8 d\right)$. Three Chl_A major QTLs ( $q C h l \_A 8 d, q C h l \_A 18 e$ and $\left.q C h l \_A 19 e\right)$ and one Chl_B major QTL $\left(q C h l \_B 7 e-1\right)$ were mapped on 


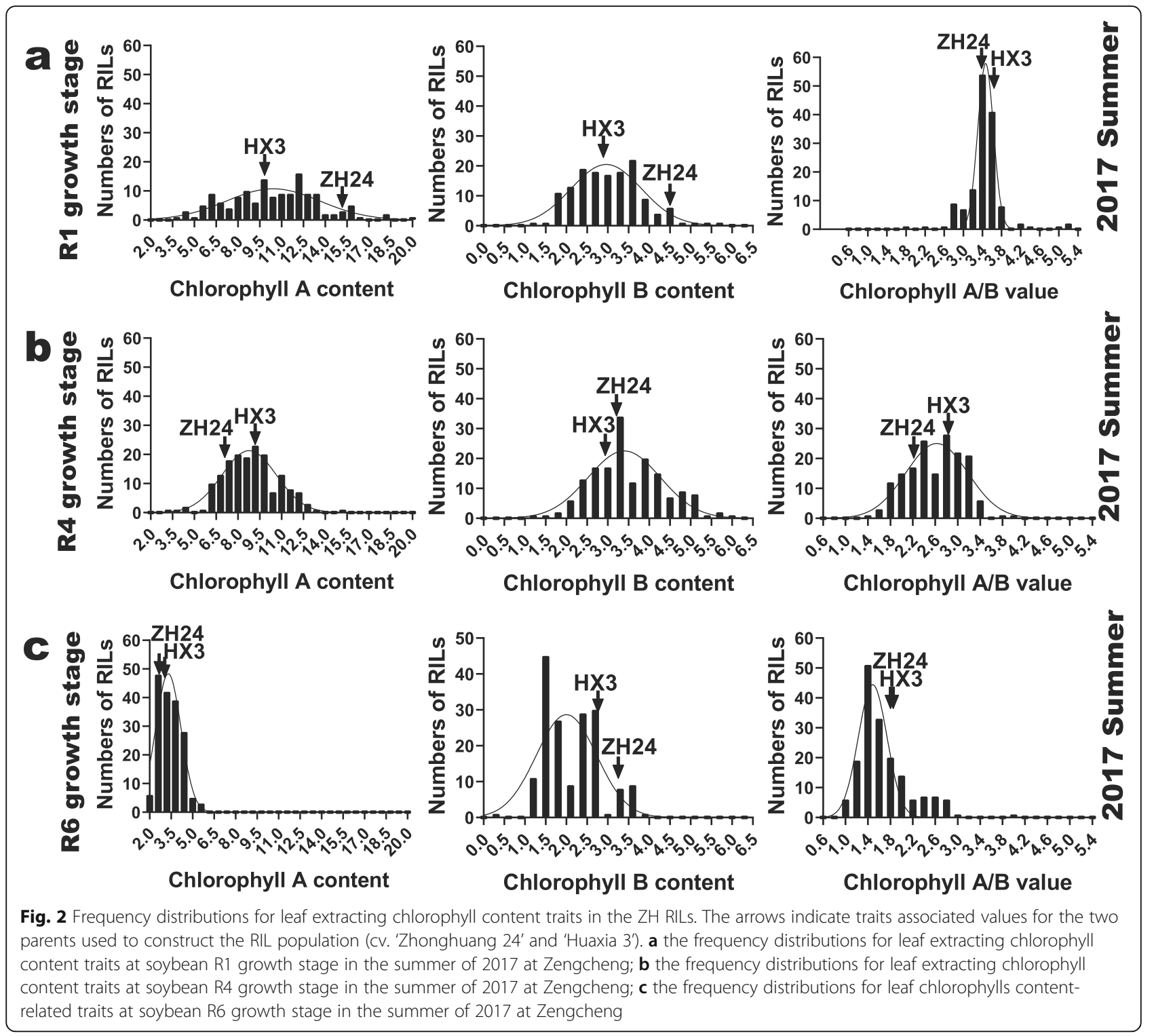

chromosomes 08, 18, 19 and 07, respectively. However, all the identified Chl_A/B QTLs were minor effect ones $\left(R^{2}<10 \%\right)$. Moreover, the 13 major QTLs (qASP1b-1, $q T S P 1 b, q T S P 2 e, q M S P 3 e, q A S P 5 d-2, q C h l \_B 7 e-1, q C h l \_$ $A 8 d, q B S P 9 e, q A S P 15 a, q M S P 15 a-1, q C h l_{-} A 18 e, q C h l_{-}$ $A 19 e$ and $q M S P 19 f)$ were highlighted in red and marked with asterisks in Fig. 3.

Explorations of important bin markers and QTL hotspots for soybean leaf chlorophyll-content traits

As is shown in Table S6 (Additional file 1), five bin markers on four soybean chromosomes (01, 02, 07 and 15) were determined to be important and each of them identified QTLs for at least two distinct chlorophyllcontent traits. Besides, bin30, bin 80 and bin 94 on chromosomes 02, 07 and 15 detected QTLs across different environments. In conclusion, the important bin markers may be valuable to detect the different chlorophyll-content QTLs throughout the environments.

According to the reported definition on QTL hotspots [24], 16 chlorophyll-content traits QTL hotspots on 12 soybean chromosomes $(01,02,03,06,07,08,11,13,15$, 16, 18 and 19) were summarized. These QTL hotspots contained at least two QTLs and were named after 'CT', which represented their regulations on different chlorophyll-content traits (Table 2). Besides, five important QTL hotspots ( $q C T 1 Z-2, q C T 2 Z-1, q C T 3 Z, q C T 7 Z$ and $q C T 15 Z-1$ ) were highlighted from the above QTL hotspots, and each of them contained at least one major QTL. As is shown in Table 2, qCT1Z-2 consisted of two major SPAD QTLs $(q A S P 1 b-1$ and $q T S P 1 b)$ that could 
Table 1 Leaf chlorophyll-content traits in the ZH RIL population across different environments

\begin{tabular}{|c|c|c|c|c|c|c|c|c|c|}
\hline \multirow[t]{2}{*}{ Traits } & \multicolumn{2}{|c|}{ Parents Average } & \multicolumn{4}{|c|}{ RILs Lines Average } & \multirow[t]{2}{*}{ Skewness } & \multirow[t]{2}{*}{ Kurtosis } & \multirow{2}{*}{$\begin{array}{l}\text { Year, } \\
\text { seasons } \\
\text { and } \\
\text { growth } \\
\text { stages }\end{array}$} \\
\hline & $\overline{\mathrm{ZH} 24^{\mathrm{a}}}$ & $H \times 3^{a}$ & Minimum $^{a}$ & Maximum $^{\mathrm{a}}$ & Mean $^{a}$ & SD & & & \\
\hline TSP & $58.94 \pm 0.82$ & $54.58 \pm 0.98$ & 39.96 & 59.92 & 52.43 & 4.28 & -0.70 & -0.43 & 2017Spr-R1 \\
\hline MSP & $48.17 \pm 1.19$ & $46.40 \pm 1.27$ & 29.50 & 55.64 & 46.35 & 4.20 & -0.30 & 0.13 & \\
\hline BSP & $43.37 \pm 1.14$ & $41.71 \pm 1.64$ & 24.58 & 51.60 & 40.55 & 4.09 & -10.00 & 0.68 & \\
\hline ASP & $50.16 \pm 0.55$ & $47.56 \pm 0.59$ & 37.30 & 54.90 & 46.46 & 3.31 & -0.23 & -0.43 & \\
\hline TSP & $58.06 \pm 0.52$ & $53.57 \pm 1.08$ & 40.92 & 60.60 & 51.34 & 3.41 & -0.16 & 0.16 & 2017Spr-R4 \\
\hline MSP & $55.37 \pm 1.43$ & $52.82 \pm 0.66$ & 37.00 & 58.46 & 47.29 & 3.27 & 0.21 & 1.17 & \\
\hline BSP & $47.06 \pm 1.35$ & $46.57 \pm 1.51$ & 35.34 & 53.60 & 42.87 & 2.90 & 0.27 & 0.74 & \\
\hline ASP & $53.50 \pm 0.44$ & $50.98 \pm 0.32$ & 39.58 & 54.70 & 47.16 & 2.59 & -0.23 & 0.42 & \\
\hline TSP & $54.94 \pm 1.24$ & $50.40 \pm 1.12$ & 35.72 & 58.40 & 49.60 & 4.59 & -0.24 & -0.85 & 2017Spr-R6 \\
\hline MSP & $48.17 \pm 0.66$ & $46.40 \pm 1.89$ & 33.50 & 54.44 & 43.72 & 4.73 & 0.25 & -0.93 & \\
\hline BSP & $44.37 \pm 1.22$ & $41.71 \pm 0.89$ & 24.58 & 47.00 & 37.83 & 4.37 & 0.48 & -0.14 & \\
\hline ASP & $49.16 \pm 0.59$ & $46.17 \pm 0.73$ & 34.20 & 50.82 & 43.71 & 3.65 & 0.02 & -0.60 & \\
\hline TSP & $44.19 \pm 1.54$ & $37.89 \pm 1.84$ & 31.00 & 45.36 & 39.34 & 2.87 & -0.30 & -0.58 & 2017Sum-R1 \\
\hline MSP & $42.90 \pm 1.18$ & $37.32 \pm 0.92$ & 29.66 & 45.84 & 38.07 & 3.22 & -0.20 & -0.26 & \\
\hline BSP & $36.47 \pm 1.09$ & $33.57 \pm 1.26$ & 22.62 & 41.40 & 33.57 & 3.44 & -0.55 & 0.42 & \\
\hline ASP & $41.19 \pm 0.62$ & $36.26 \pm 1.17$ & 30.02 & 43.34 & 37.00 & 2.37 & -0.29 & 0.27 & \\
\hline Chl_A $A^{a}$ & $15.12 \pm 1.09$ & $9.88 \pm 0.60$ & 3.84 & 20.26 & 10.39 & 3.12 & 0.26 & 0.04 & \\
\hline Chl_B ${ }^{a}$ & $4.49 \pm 0.27$ & $2.89 \pm 0.26$ & 1.17 & 5.79 & 3.01 & 0.82 & 0.52 & 0.43 & \\
\hline Chl_A/B & $3.41 \pm 0.30$ & $3.55 \pm 0.42$ & 1.89 & 5.56 & 3.43 & 0.45 & 1.50 & 8.33 & \\
\hline TSP & $42.39 \pm 1.71$ & $40.24 \pm 1.02$ & 30.90 & 54.22 & 41.24 & 3.81 & 0.25 & 0.54 & 2017Sum-R4 \\
\hline MSP & $42.42 \pm 0.96$ & $46.23 \pm 1.19$ & 29.70 & 52.18 & 41.50 & 4.40 & 0.04 & -0.37 & \\
\hline BSP & $36.22 \pm 1.25$ & $35.89 \pm 1.07$ & 26.88 & 55.94 & 37.62 & 4.36 & 0.10 & 0.92 & \\
\hline ASP & $40.34 \pm 0.33$ & $40.79 \pm 0.54$ & 30.84 & 48.14 & 40.12 & 3.43 & -0.09 & -0.38 & \\
\hline Chl_A ${ }^{a}$ & $7.04 \pm 0.55$ & $8.93 \pm 0.36$ & 2.97 & 15.29 & 8.92 & 1.95 & 0.12 & 0.50 & \\
\hline Chl_B ${ }^{a}$ & $3.24 \pm 0.20$ & $3.10 \pm 0.07$ & 1.22 & 6.70 & 3.55 & 0.96 & 0.54 & 0.50 & \\
\hline Chl_A/B & $2.23 \pm 0.28$ & $2.88 \pm 0.11$ & 1.34 & 4.07 & 2.59 & 0.49 & -0.09 & -0.40 & \\
\hline TSP & $41.85 \pm 1.38$ & $41.33 \pm 0.73$ & 31.00 & 52.94 & 41.21 & 4.60 & 0.00 & -0.56 & 2017Sum-R6 \\
\hline MSP & $40.46 \pm 0.95$ & $41.73 \pm 1.23$ & 23.56 & 52.80 & 41.02 & 4.42 & -0.50 & 0.92 & \\
\hline BSP & $35.72 \pm 0.80$ & $33.10 \pm 0.85$ & 22.24 & 44.30 & 32.72 & 3.75 & -0.42 & 0.71 & \\
\hline ASP & $39.34 \pm 0.69$ & $38.72 \pm 0.81$ & 29.58 & 46.30 & 38.51 & 3.26 & -0.13 & -0.55 & \\
\hline Chl_A $A^{a}$ & $5.17 \pm 0.25$ & $4.73 \pm 0.31$ & 2.17 & 5.65 & 3.38 & 0.77 & 0.35 & -0.47 & \\
\hline Chl_B ${ }^{a}$ & $3.21 \pm 0.40$ & $2.83 \pm 0.31$ & 0.43 & 3.76 & 2.12 & 0.68 & 0.56 & -0.31 & \\
\hline Chl_A/B & $1.75 \pm 0.30$ & $1.76 \pm 0.24$ & 0.90 & 3.91 & 1.68 & 0.48 & 1.38 & 2.41 & \\
\hline
\end{tabular}

TSP Top leaves SPAD value, MSP Mid leaves SPAD value, BSP Bottom leaves SPAD value, ASP Average SPAD value, ChI_A Chlorophyll a content, Chl_BChlorophyll b content, ChI_A/B Chlorophyll a/b ratio, ZH24 'Zhonghuang 24', HX3 'Huaxia 3', ${ }^{a} \mathrm{mg} / \mathrm{g}, 2017$ Spr: the spring of 2017, 2017Sum: the summer of 2017, R1 R1 growth stage, $R 4$ R4 growth stage, $R 6$ R6 growth stage

explain the phenotypic variation ranging from 11.97 to $16.55 \%$. And $q C T 2 Z-1$ was anchored by three adjacent bin markers on chromosome 02 and contained four SPAD QTLs. Comparably, $q C T 3 Z$ was in an interval from $36,603,803$ to $37,138,700 \mathrm{bp}$ on chromosome 03 and contained one QTL for MSP and one QTL for ASP. Furthermore, $q C T 7 Z$ and $q C T 15 Z-1$ are both important
QTL hotspots, which included different SPAD and extracting chlorophyll content QTLs. And $q C T 7 Z$ contained two extracting chlorophyll content QTLs and three SPAD QTLs and located in a block from 15,667, 842 to $16,803,624 \mathrm{bp}$ on chromosome 07. Moreover, qCT15Z-1 consisted of two SPAD QTLs and one extracting chlorophyll content QTL. Notably, qCT15Z-1 


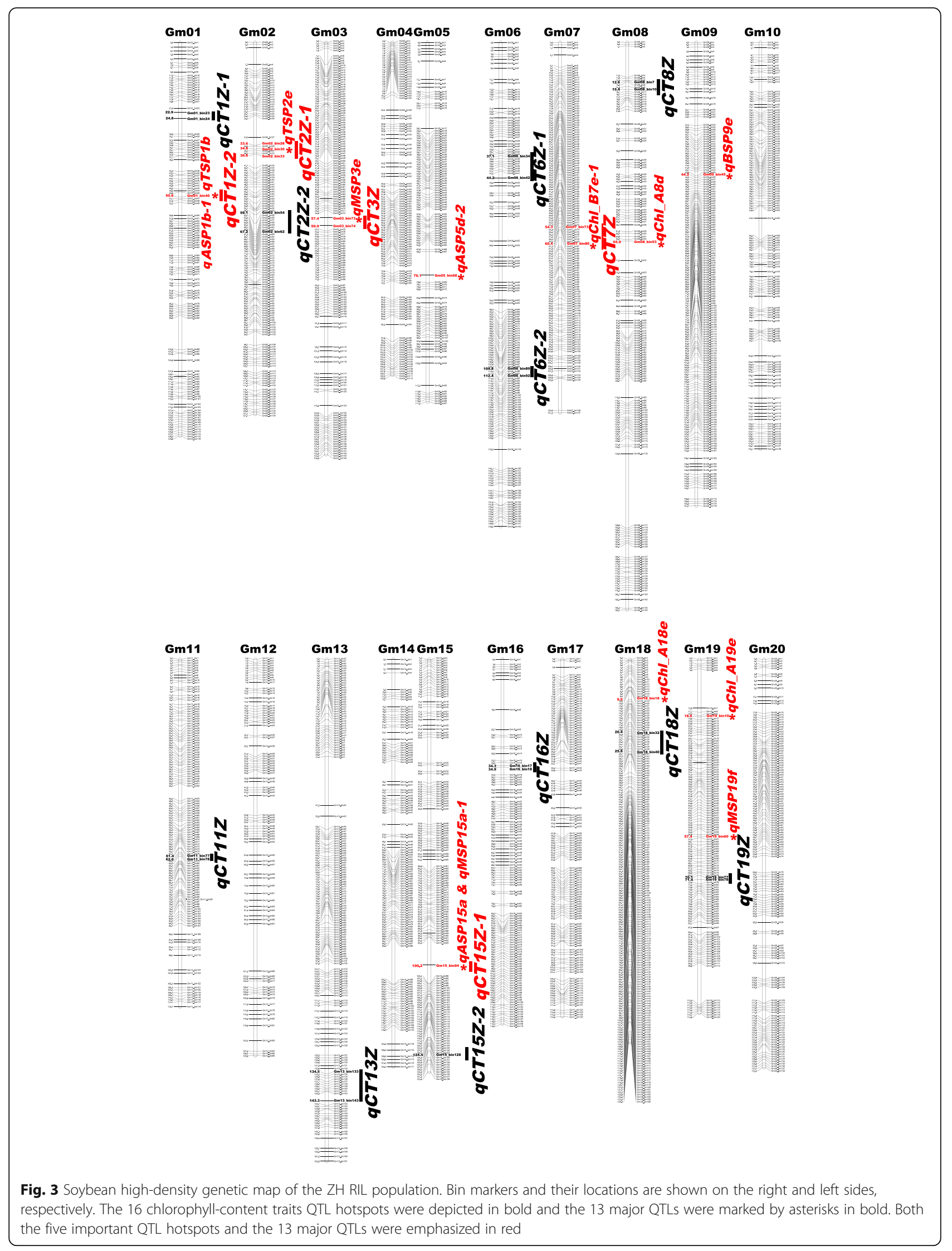


Table 216 QTL hotspots associated with leaf chlorophyll-content traits detected in the ZH RIL population

\begin{tabular}{|c|c|c|c|c|c|c|c|c|c|c|}
\hline QTL hotspot $^{\mathrm{a}}$ & QTL name $^{b}$ & $\mathrm{Chr}^{\mathrm{c}}$ & $\begin{array}{l}\text { Bin } \\
\text { name }\end{array}$ & Clv1.1 (bp) $)^{d}$ & $\begin{array}{l}\text { Bin length } \\
\text { (bp) }\end{array}$ & $\begin{array}{l}\text { Position } \\
\text { (cM) }\end{array}$ & $\operatorname{LOD}^{\mathrm{e}}$ & $A D D^{f}$ & $R^{2}(\%)^{g}$ & Clv2.0 (bp) ${ }^{h}$ \\
\hline \multirow[t]{2}{*}{ qCT1Z-1 } & qBSPle & 1 & Bin23 & 3,014,519-3,035,286 & 20,768 & 22.9 & 2.51 & -1.08 & 5.81 & $3,037,245-3,038,559$ \\
\hline & qASP1f & 1 & Bin24 & $3,035,287-3,300,327$ & 265,041 & 24.8 & 4.02 & -1.06 & 9.76 & $3,060,271-3,302,133$ \\
\hline \multirow[t]{2}{*}{ qCT1Z-2 } & qASPIb-1 & 1 & Bin46 & $11,517,849-26,055,466$ & $14,537,618$ & 50.6 & 6.84 & 1.47 & 16.55 & $11,591,808-24,499,599$ \\
\hline & aTSP1b & 1 & Bin46 & $11,517,849-26,055,466$ & $14,537,618$ & 50.6 & 5.13 & 1.66 & 11.97 & $11,591,808-24,499,599$ \\
\hline \multirow[t]{4}{*}{ qCT2Z-1 } & qASP2e & 2 & $\operatorname{Bin} 28$ & $6,826,912-6,946,505$ & 119,594 & 33.6 & 2.60 & -0.84 & 5.84 & $6,909,163-7,031,971$ \\
\hline & qBSP2d & 2 & Bin30 & $7,060,106-7,152,841$ & 92,736 & 34.8 & 3.66 & -1.07 & 8.79 & $7,145,546-7,228,940$ \\
\hline & qTSPZe & 2 & Bin30 & $7,060,106-7,152,841$ & 92,736 & 34.8 & 4.23 & -1.25 & 10.08 & $7,145,546-7,228,940$ \\
\hline & $q B S P 2 f$ & 2 & Bin33 & $7,454,452-9,601,062$ & $2,146,611$ & 38.6 & 2.77 & -1.00 & 6.93 & $7,539,451-9,689,680$ \\
\hline \multirow[t]{2}{*}{ qCT2Z-2 } & qChl_AvB2f & 2 & Bin54 & $15,046,557-15,213,830$ & 167,274 & 59.1 & 3.10 & 0.13 & 7.54 & $15,251,037-15,422,632$ \\
\hline & qChl_B2f & 2 & Bin62 & $16,848,795-27,416,648$ & $10,567,854$ & 67.2 & 2.50 & -0.16 & 5.10 & $17,128,244-26,385,905$ \\
\hline \multirow[t]{2}{*}{ qст3Z } & qMSP3e & 3 & Bin73 & $36,603,803-36,725,014$ & 121,212 & 59.4 & 3.94 & 1.41 & 10.06 & $34,589,840-347,02,370$ \\
\hline & qASP3e & 3 & Bin75 & $37,109,279-37,138,700$ & 29,422 & 61.7 & 3.07 & 0.92 & 6.85 & $35,106,012-35,113,620$ \\
\hline \multirow[t]{2}{*}{ qCT6Z-1 } & qASPGf & 6 & Bin34 & $5,908,302-5,959,466$ & 51,165 & 37.1 & 2.54 & -0.80 & 6.07 & $5,914,573-5,964,561$ \\
\hline & qASP6d & 6 & Bin42 & $6,959,298-7,246,025$ & 286,728 & 44.2 & 3.92 & -0.75 & 9.14 & $6,972,002-7,247,613$ \\
\hline \multirow[t]{2}{*}{ qCT6Z-2 } & aTSP6b & 6 & Bin89 & $15,950,387-16,194,517$ & 244,131 & 109.8 & 3.10 & 0.93 & 7.45 & $16,011,413-16,229,680$ \\
\hline & qMSPGe-1 & 6 & Bin92 & $16,664,681-16,817,080$ & 152,400 & 112.4 & 3.66 & 1.82 & 8.86 & $16,709,212-16,859,338$ \\
\hline \multirow[t]{5}{*}{ qCT7Z } & qMSP7a-1 & 7 & Bin73 & $15,667,842-15,734,307$ & 66,466 & 54.3 & 3.23 & -1.18 & 7.21 & $15,769,608-15,813,498$ \\
\hline & qASP7a & 7 & Bin80 & $16,504,261-16,803,624$ & 299,364 & 60.4 & 2.74 & -0.84 & 6.07 & $16,597,814-16,889,324$ \\
\hline & $q C h \mid B B 7 e-1$ & 7 & Bin80 & $16,504,261-16,803,624$ & 299,364 & 60.4 & 5.05 & -0.39 & 12.75 & $16,597,814-16,889,324$ \\
\hline & qChl_A/B7d & 7 & Bin80 & $16,504,261-16,803,624$ & 299,364 & 60.4 & 2.83 & -0.18 & 8.69 & $16,597,814-16,889,324$ \\
\hline & aMSP7a-2 & 7 & Bin80 & $16,504,261-16,803,624$ & 299,364 & 60.4 & 2.58 & -1.06 & 5.81 & $16,597,814-16,889,324$ \\
\hline \multirow[t]{2}{*}{ qст8Z } & qTSP8f-1 & 8 & Bin7 & $2,225,026-2,271,343$ & 46,318 & 12.6 & 3.10 & 1.30 & 7.64 & $2,238,240-2,275,653$ \\
\hline & aMSP8b & 8 & Bin10 & $2,712,995-2,737,327$ & 24,333 & 15.4 & 2.80 & 0.98 & 7.05 & $2,719,028-2,741,745$ \\
\hline \multirow[t]{2}{*}{ qCT11Z } & qChl_AvB11e-2 & 11 & Bin77 & $16,152,967-16,449,587$ & 296,621 & 61.4 & 2.91 & 0.14 & 7.16 & $26,145,820-26,431,037$ \\
\hline & aBSP11e & 11 & Bin78 & $16,449,588-16,610,503$ & 160,916 & 62.6 & 3.07 & -1.18 & 7.10 & $26,412,450-26,574,724$ \\
\hline \multirow[t]{2}{*}{ qCT13Z } & qASP13b-1 & 13 & Bin133 & $39,361,093-39,386,817$ & 25,725 & 134.5 & 2.74 & -0.67 & 6.30 & $40,532,836-40,567,479$ \\
\hline & qASP13b-2 & 13 & Bin143 & $40,173,283-40,428,061$ & 254,779 & 143.3 & 2.71 & -0.66 & 6.25 & $41,618,514-41,874,899$ \\
\hline \multirow[t]{3}{*}{ qCT15Z-1 } & qASP15a & 15 & Bin94 & $16,683,420-17,383,420$ & 700,001 & 100.2 & 5.27 & -1.19 & 11.94 & $16,695,707-17,350,040$ \\
\hline & qChI_B15f-1 & 15 & Bin94 & $16,683,420-17,383,420$ & 700,001 & 100.2 & 2.55 & -0.17 & 5.71 & $16,695,707-17,350,040$ \\
\hline & qMSP15a-1 & 15 & Bin94 & $16,683,420-17,383,420$ & 700,001 & 100.2 & 5.94 & -1.63 & 13.86 & $16,695,707-17,350,040$ \\
\hline \multirow[t]{2}{*}{ qCT15Z-2 } & qChl_A15f & 15 & Bin128 & $48,582,583-48,741,529$ & 158,947 & 124.4 & 3.68 & 0.23 & 8.99 & $49,382,502-49,534,743$ \\
\hline & qChl_B15f-2 & 15 & Bin128 & $48,582,583-48,741,529$ & 158,947 & 124.4 & 3.97 & 0.20 & 8.94 & $49,382,502-49,534,743$ \\
\hline \multirow[t]{2}{*}{ qCT16Z } & qTSP16e & 16 & Bin17 & $5,525,628-5,588,607$ & 62,980 & 34.4 & 3.29 & 1.08 & 7.69 & $5,551,673-5,607,211$ \\
\hline & qASP16e & 16 & Bin18 & $5,588,608-5,809,086$ & 220,479 & 34.9 & 3.30 & 0.96 & 7.61 & $5,618,869-5,828,808$ \\
\hline \multirow[t]{2}{*}{ qCT18Z } & qMSP18f-1 & 18 & Bin32 & $3,157,973-3,350,322$ & 192,350 & 20.4 & 3.41 & 1.24 & 7.68 & $3,182,661-3,349,093$ \\
\hline & qMSP18f-2 & 18 & Bin40 & $4,116,314-4,142,492$ & 26,179 & 25.6 & 3.30 & 1.21 & 7.44 & $4,139,387-4,161,508$ \\
\hline \multirow[t]{2}{*}{ qCT19Z } & qTSP19f & 19 & Bin77 & $40,662,371-40,701,058$ & 38,688 & 70.1 & 3.28 & 1.33 & 8.17 & $40,859,609-40,891,331$ \\
\hline & qMSP19d & 19 & Bin78 & $40,701,059-40,809,377$ & 108,319 & 71.4 & 2.66 & -0.85 & 6.57 & $40,896,924-41,007,822$ \\
\hline
\end{tabular}

The name of the QTL hotspot is a composite of multiple chlorophyll-content traits (CT); Zhonghuang $24 \times$ Huaxia 3 RIL population (Z)

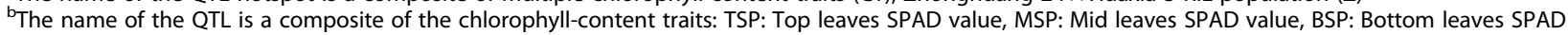
value, ASP: Average SPAD value, Chl_A: Chlorophyll a content, Chl_B:Chlorophyll b content, Chl_A/B: Chlorophyll a/b ratio; a: the R1 growth stage in the spring of 2017 at Zengcheng; b: the R4 growth stage in the spring of 2017 at Zengcheng; c: the R6 growth stage in the spring of 2017 at Zengcheng; d: the R1 growth stage in the summer of 2017 at Zengcheng; e: the R4 growth stage in the summer of 2017 at Zengcheng; $f$ : the R6 growth stage in the summer of 2017 at Zengcheng

${ }^{c} \mathrm{Chr}$ refers to the chromosome

${ }^{\mathrm{d}}$ The physical position corresponding to the $95 \%$ confidence interval for the detected QTL based on Glyma.Wm82. a1. v1. 1 gene model

eLOD indicates the logarithm of the odds score

'Positive and negative values indicated additive effect by the alleles of 'Zhonghuang 24 ' and 'Huaxia 3 ', respectively

${ }^{9} R^{2}$ indicates the phenotypic variance explained by individual QTL

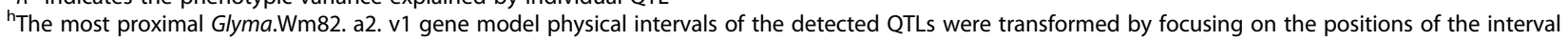
nearest $3^{\prime}$ and $5^{\prime}$ ending genes 
was anchored by the bin94 marker on chromosome 15 across distinct environments. The 16 chlorophyllcontent traits QTL hotspots were marked in bold on the high-density genetic map. For the important five QTL hotspots, we further depicted them in red (Fig. 3).

\section{Relations between the identified QTLs in the present research and the previous studies}

Previously, there were 24 published SPAD QTLs spanned on 12 soybean chromosomes on SoyBase (Additional file 1: Table S7) [28-31]. In this study, we analyzed the relations between the identified soybean leaf chlorophyll content traits QTLs and the published SPAD QTLs (Additional file 1: Table S8). As a result, 17 detected QTLs were associated with 11 reported QTLs. And most identified QTLs in the current research were novel ones for soybean leaf content traits.

Various yield-associated traits like lodging, plant height, seed set (also named seed per pod), seed weight, internode length, seed yield, could affect soybean yield [29, 32-45]. In a former study, Liu et al. utilized the same mapping RIL (the ZH RIL) population and elegantly identified QTLs for different yield and qualityrelated traits [24]. Based on the identical mapping population and the genetic map, we further explored the correlations between the chlorophyll-content QTLs in this study and the yield-related traits QTLs reported by Liu et al. [24]. As a result, 19 identified chlorophyll-content QTLs spanned on eight chromosomes $(04,06,07,08,11$, 15,17 and 19) were found to be associated with the 25 published yield-related QTLs (Fig. 4). Concomitantly, both the detected chlorophyll-content traits major QTLs and the published yield-related traits major QTLs were highlighted with the purple diamond tags on the genetic linkage map. Besides, different recorded yield-related traits QTLs on SoyBase were also found in the genetic regions of the five important QTL hotspots in this study (Additional file 1: Table S9). In conclusion, the correlated chlorophyllcontent and yield-related QTLs in the present and previous studies, especially the major QTLs, may be valuable to pave the way for soybean high-yielding breeding.

\section{Gene ontology (GO) enrichment analyses, candidate gene predictions, candidate gene genomic locations and gene structure characteristics}

To gain an in-depth understanding of which genes may relate to soybean leaf chlorophyll-content traits, we retrieved the gene calls in the genetic blocks of the 13 major QTLs and the five important QTL hotspots. Totally 515 and 410 annotated genes were found in the corresponding hereditary intervals of the major QTLs and important QTL hotspots, respectively (Additional file 1: Table S10 and Table S11). Among the annotated genes, 384 were corresponded to at least one GO annotation. Moreover, these genes were predicted to be associated with various biological processes and could further classify into 21 categories, including signaling, regulation of biological process, biological regulation, cellular process, signaling process, metabolic process, localization, response to stimulus, transporter activity, transcription regulator activity, structural molecule activity, catalytic activity, binding, enzyme regulator activity, electron carrier activity, macromolecular complex, cell, cell part, organelle and organelle part (Additional file 1: Table S12). Some biological processes such as metabolic processes, catalytic activity, and especially transcription regulator activities are crucial for gene expression and metabolites in different organisms. Furthermore, the GO enrichment terms in Table S12 (Additional file 1) were filtered by $P<0.05$ and gene number over five in Table S13 (Additional file 1). As a result, $17 \mathrm{GO}$ terms in the molecular function class and eight GO terms in the biological process were filtered. And the filtered GO terms were depicted in Fig. S3 (Additional file 4).

Based on the GO enrichment analyses, the gene annotations on SoyBase (Additional file 1: Table S14) and the gene expression levels on SoyBase and Phytozome (https://phytozome.jgi.doe.gov/pz/portal.html), we predicted six candidate genes for soybean leaf chlorophyll-content traits. Among them, Glyma01g15506 was in the genetic block of two major QTLs ( $q T S P 1 b$ and $q A S P 1 b-1)$ and the two major QTLs were identified by the same bin marker in qCT1Z-2. Moreover, Glyma02g08910 and Glyma02g11110 were originated from the different hereditary regions of $q C T 2 Z-1$. Furthermore, Glyma07g15960 was predicted as a putative functional gene in $q C T 7 Z$. Besides, Glyma15g19670 and Glyma15g19810 were two adjacent genes obtained from the identical genetic interval of two major QTLs ( $q A S P 15 a$ and $q M S P 15 a-1$ ) in qCT15Z-1. The detailed genomic locations, conserved domains and gene structures of the candidate genes were depicted in Fig. 5. The genomic positions of the candidate genes were stepwise displayed from the anchored bin markers on soybean chromosomes to the candidate genes in the bin markers. The bin markers and the candidate genes were displayed at the ratios based on the soybean genome physical locations. According to Fig. 5, Glyma01g15506, Glyma02g08910, Glyma02g11110, Glyma07g15960, Glyma15g19670 and Glyma15g19810 contained plastid-lipid associated protein (PAP) fibrillin domain, chlorophyll A-B binding (ChloroA B-bind) domain, threonine-protein kinase (Pkinase_Tyr) domain, nicotinamide adenine dinucleotide (NAD) binding domain, aldehyde dehydrogenase (Aldedh) domain and chlorophyll A-B binding domain, respectively.

\section{Discussion}

Variations in soybean leaf chlorophyll-content traits Chlorophylls are the major photosynthetic pigments acting as the main absorbers of harvesting light in plants 


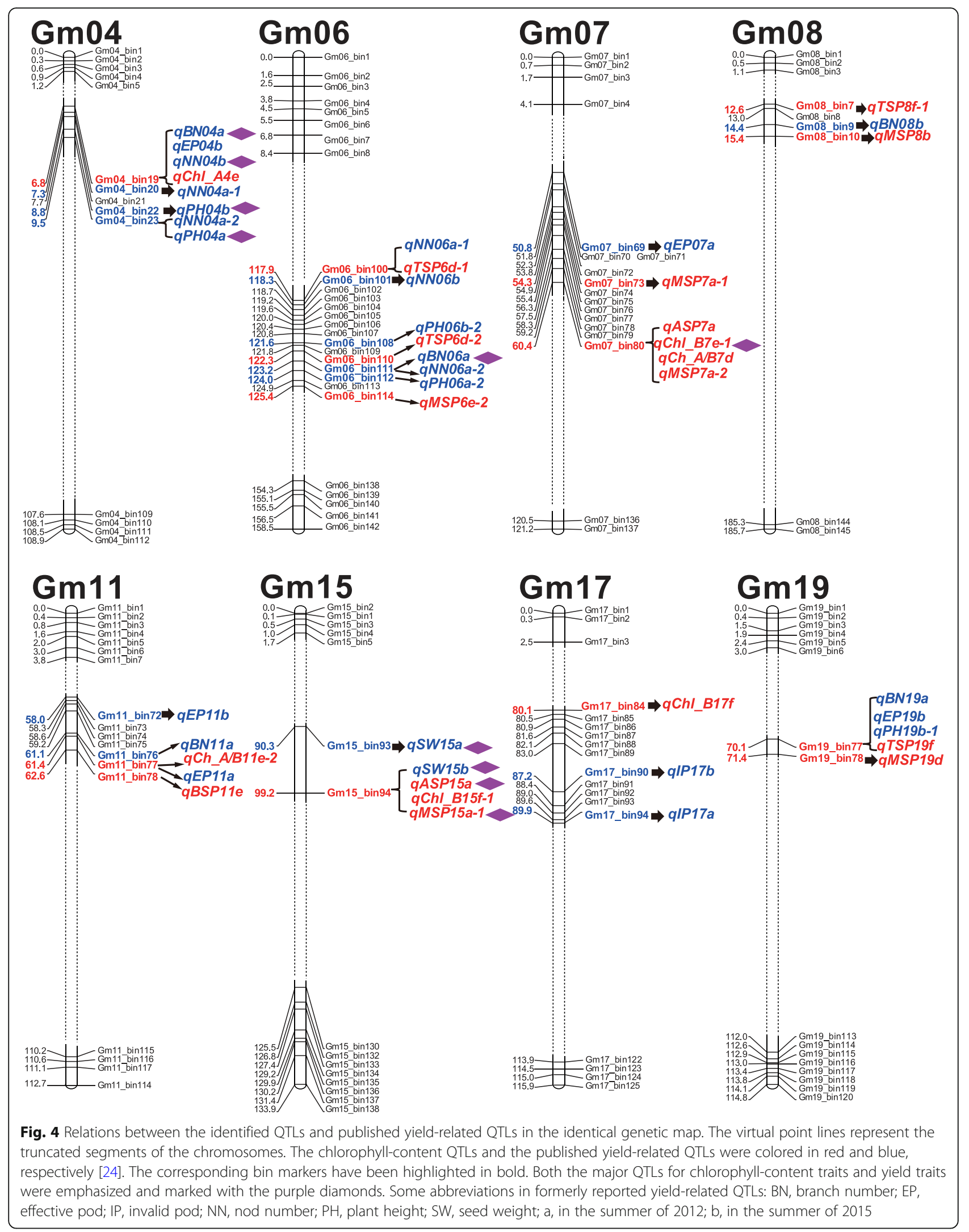




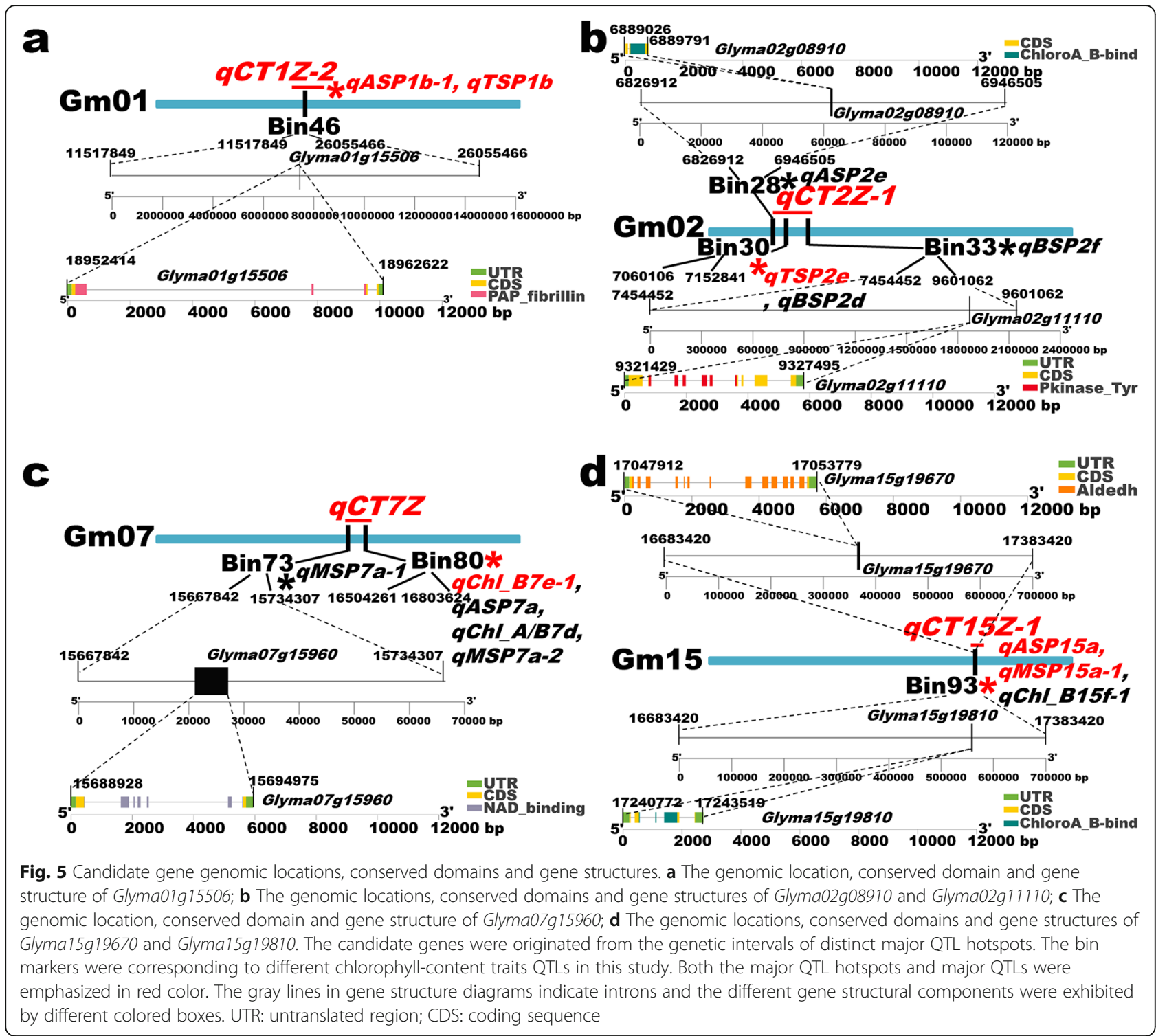

[46, 47]. Soybean chlorophyll-content traits are complex quantitative traits involving in the dual-effects of hereditary and environmental factors $[48,49]$. As is shown in Table 1, the phenotypic data of chlorophyll-content traits fluctuated with the soybean growth stages. For MSP, BSP and ASP, the phenotypic data dynamically increased from the R1 to R4 growth stages and then decreased from the R4 to R6 growth stages. Interestingly, phenotypic data of TSP, Chl_A, Chl_B and Chl_A/B gradually reduced with the three soybean reproductive growth stages. Furthermore, for the specific trait, the paternal soybeans generally showed lower values than those of maternal ones. Taken together, we speculated that soybean leaf chlorophyll-contents may be determined by the genetic differences in the RILs and are regulated by distinct functional genes during different growth stages $[25,50]$. Moreover, according to the correlation analyses in Table S1 (Additional file 1), most chlorophyll-content traits were highly correlated under specific chlorophyll assessing methods. Hence, the regulating genes may be pleiotropic or closely linked [51]. Both the extracted-based or SPAD-based methods are popular approaches in chlorophyll assessments. However, the phenotypic data under distinct evaluating approaches show no obvious correlation, which may due to the different mechanisms and phenotyping focuses of the two chlorophyll assessing methods in this study. For the mechanisms, the SPAD testing method is a nondestructive way that measures light transmittance of the leaf in the red and infrared wavelengths at 650 and 940 $\mathrm{nm}$ to assess the relative total chlorophyll content in leaves [5]. Whereas, the extracted-based method is a 
destructive approach detecting by a spectrophotometer depending on different light wavelengths (645 and 663 $\mathrm{nm})$ to assess different components of leaf chlorophylls (Chl_A and Chl_B) [52]. For the phenotyping focuses, SPAD testing in this study was focused on different leaves from distinct positions of soybean plants. Whereas, for the extracted-based method, we sampled the top position leaves (the fully developed middle leaflets of the 3rd node on the main stem counting down from the top) for soybean leaf pigment extractions. In most cases, the plants from different soybean lines of the RIL population exhibited diverse plant architectures. And the upper position leaves of the plant shaded more or less on the lower position ones throughout different soybean lines of the RIL population, which may affect the SPAD testing reads as well as the correlations between the two chlorophyll assessing methods. Besides, phenotypic data at the same soybean growth stages but different planting seasons exhibited variations, and this may highlight the effects of environmental factors on relevant traits. In all, variations of the soybean leaf chlorophyll-content traits support the reported characteristics of quantitative traits [29-31].

\section{Main effective factors for QTL mapping}

QTL mapping is commonly used to identify genomic regions responsible for important quantitative and quality traits and has been regarded as a powerful tool for favorable alleles digging in the crop improvement process. Generally, QTL mapping depends on detecting the correlations between genetic markers and phenotypic traits in a segregating population $[53,54]$. This study aimed to explore QTLs for soybean leaf chlorophyll-content traits. Many factors such as the types and the scales of the mapping populations, parental genetic backgrounds, hereditary capacities, genetic markers densities and distributions, environmental factors could affect the mapping precisions. Despite 18 bi-parental SPAD QTLs were recorded on SoyBase, however, the limitations of mapping populations and technologies restricted the discovering of important QTLs or genes. To avoid the former disadvantages, we improved them from different aspects, including the application of an $\mathrm{F}_{12}$ advanced RIL population with sufficient segregation lines (164 ZH RILs) and its RAD-seq based high-density genetic bin marker map. Hence, we gathered more accurate hereditary information for the target traits QTLs. Some chlorophyllcontent traits QTLs were identified by the bin markers that spanned relatively large genetic intervals (Additional file 1: Table S6). For instance, $q A S P 1 b-1$ and $q T S P 1 b$ were detected by the bin 46 marker on chromosome 01 . Although considerable SNPs (51 SNPs) existed in the bin marker (Additional file 1: Table S3), however, this bin marker spanned a large genetic interval $(14,537,618$ bp). One possible cause is that the bin marker may locate in a heterochromatic region, where the frequency of the recombination events is low [55]. The practicable strategy to further fine map these QTLs is to increase the mapping population size and to screen for the valuable recombinant lines [56]. Notably, the parental soybeans broadly exhibited differences in the chlorophyll-content traits (Table 1, Figs. 1 and 2). In most cases, 'Zhong Huang 24' (maternal soybean) took the surpassing values compared to those of 'Huaxia 3' (paternal soybean). Previous studies demonstrated that the significant positive correlations between seed yield and leaf chlorophyll content were usually found in soybean reproductive stages [7]. In this study, we focused on three representative important stages (R1, R4 and R6) throughout the soybean early, medium and late reproductive stages for the phenotypic data collections. Furthermore, we aggregately analyzed target traits with two chlorophyll valuating approaches (SPAD testing and leaf extracting assessing) in the spring and summer of 2017. Both two methods were widely adopted in leaf chlorophyll evaluations $[2,5]$. The SPAD testing method is fast and convenient for relatively total leaf chlorophyll measurements. For the analyses of chlorophyll-related components, it is recommended to carry out the leaf extracting method $[2,5]$. In conclusion, the detected QTLs in the current study expanded the QTLs for soybean leaf chlorophyll-content traits and may be beneficial to soybean MAS breeding for associated soybean leaf chlorophyll-content traits.

\section{Correlations between the identified chlorophyll-content traits QTLs and reported diverse traits QTLs}

Compared to the genetic regions of recorded SPAD QTLs on SoyBase, most QTLs identified in this study were in novel hereditary regions. Due to relatively low density and uneven marker distributions of the former genetic linkage maps, these genetic regions may not be detected. Hence, our findings may facilitate to enrich the genetic information for soybean leaf chlorophyll-content traits QTLs.

Soybean is a crucial crop abundant with healthy protein and oil, and high yield is one of the most important targets in soybean breeding $[25,57]$. Early studies turned out that the soybean leaf chlorophyll contents could be positively correlated to soybean yield [6, 7]. Previously, the ZH RIL population and the high-density bin marker map were adopted to detect distinct yield-related traits QTLs [24]. In this study, we carried out comprehensive comparisons between the identified chlorophyll-content traits QTLs and the published yield-related QTLs. The results were schematically presented in Fig. 4, which may reveal the potential relationships between the 
chlorophyll-contents QTLs and yield-related QTLs. For instance, the bin 19 marker on soybean chromosome 04 identified a QTL for Chl_A in this study. And this bin marker was also associated with a reported QTL for the effective pod (EP) and two published major QTLs for branch number $(\mathrm{BN})$ and nod number $(\mathrm{NN})$ [24]. Moreover, the bin94 marker on chromosome 15 detected two major QTLs for ASP and MSP, and this bin marker was associated with reported QTLs for seed weight (SW). Besides, we found some recorded yield-related QTLs on SoyBase located in genetic intervals of the five important QTL hotspots for chlorophyll-content traits (Additional file 1: Table S9). This study focused on the QTL mapping of distinct soybean leaf chlorophyll-content traits and we also investigated the relations between the identified QTLs for soybean leaf chlorophyll-content traits in the current study and the early reported QTLs for soybean yield-related traits. However, future phenotyping and correlation analyses between the soybean leaf chlorophyll-content traits and relevant yield traits still need to be performed to further explore the underlying relations between leaf chlorophyll content and soybean yield.

\section{Six candidate genes for the chlorophyll-content traits}

The leaf chlorophyll contents were determined by the dynamically biosynthesis and metabolism of chlorophylls in plant leaves [58]. Based on the gene annotations and expression levels of the identified genes, we predicted six candidate genes for chlorophyll-content traits in the hereditary intervals of the major QTLs and the QTL hotspots. In tomato, earlier research reported that fibrillin affected plastid ultrastructures and pigment contents [59]. In this study, Glyma01g15506 was predicted to encode a plastid-lipid associated protein (PAP) in the fibrillin protein family, which was extracted from the identical genetic region of two major QTLs ( $q$ TSP $1 b$ and $q A S P 1 b-1)$ in $q C T 1 Z-2$. And this gene might affect the chlorophyll contents in soybean leaves. Another two putative genes, Glyma02g08910 and Glyma02g11110, were derived from the hereditary intervals of $q C T 2 Z-1$. The nuclear $C A B$ (chlorophyll A-B binding) gene families in plant encoded 20 to $24 \mathrm{kD}$ proteins, which spanned chloroplast thylakoid membranes and coordinated distinct chlorophylls and carotenoids [60]. Glyma02g08910 was responsible for a chlorophyll A-B binding protein, which was associated with the absorption and transfer of the energy absorbed from light photons between photosystem reaction centers [61]. And it could be regarded as one of the candidate genes that affecting soybean leaf chlorophylls. Glyma02g11110 encoded a serine/threonine-protein kinase and was annotated to be associated with the chlorophyll catabolic process on SoyBase (Additional file 1: Table S14). In a previous study, Sun et al. overexpressed one wild soybean serine/threonineprotein kinase gene (GSSRK) in Arabidopsis. As a result, the transgenic Arabidopsis lines exhibited higher chlorophyll contents and improving salt tolerance abilities compared to those in wild type Arabidopsis [62]. Hence, we predicted Glyma02g11110 as a candidate gene that may affect the chlorophyll contents in soybean leaves. Furthermore, Glyma15g19670 and Glyma15g19810 were two neighboring candidate genes, which were obtained from the same genetic regions of two major QTLs ( $q A S P 15 a$ and $q M S P 15 a-1)$ in $q C T 15 Z-1$. Coincidently, Glyma15g19810 was the candidate gene for soybean leaf chlorophyll contents, which encoded a chlorophyll A-B binding protein. Previously, it was reported that overexpressed a grapevine aldehyde dehydrogenase gene (ALDH2B8) in Arabidopsis could improve the leaf chlorophyll contents in the transgenic line under abiotic stresses [63]. Accordingly, we predicted Glyma15g19670 as a candidate gene, which was from the soybean aldehyde dehydrogenase gene family and was annotated to participate in the chlorophyll catabolic process on SoyBase (Additional file 1: Table S14). Notably, the chlorophyll content was reported to be related to the nitrogen supply in soybean leaves [64]. And we further speculated Glyma07g15960 from $q C T 7 Z$, and this gene encoded a nitrogen metabolic regulation protein and was annotated to be associated with the chlorophyll biosynthetic process on SoyBase (Additional file 1: Table S14). Besides, all candidate genes were predicted relatively high gene expression levels in soybean leaf tissues on SoyBase or Phytozome. The six predicted genes should be probed into foresighted functional validations in the future. To sum up, the putative candidate genes may be useful for promoting the research on the hereditary basis of chlorophyllcontent traits in soybean leaves.

\section{Conclusions}

In this study, we mapped QTLs of seven soybean leaf chlorophyll-content traits by utilizing a genotyped advanced recombinant inbred line population $(\mathrm{ZH}$, Zhonghuang $24 \times$ Huaxia 3 ) and its well-constructed high-density genetic map. A total of 78 target traits QTLs were identified and most detected QTLs were novel QTLs for soybean leaf chlorophyll-content traits. Moreover, 13 major QTLs and five important QTL hotspots were classified. Besides, six putative candidate genes were predicted from the hereditary regions of the major QTLs and important QTL hotspots. The identified QTLs and candidate functional genes may directly or indirectly affect the soybean leaf chlorophyll contents in soybean leaves and facilitate future soybean MAS breeding. 


\section{Methods}

\section{Plant materials and field trials}

A ZH RIL population with 164 RILs was developed from a cross between 'ZhongHuang 24' (ovule parent) and 'Huaxia 3' (pollen parent) using a single seed descent (SSD) method derived from individual $F_{2}$ plants [27]. 'Zhonghuang 24' is a variety from the Institute of Crop Sciences, Chinese Academy of Agricultural Sciences, which adapts to the Huang-Huai-Hai region. 'Huaxia 3' is a high-yield soybean cultivar obtained from South China Agricultural University. The $\mathrm{F}_{12} \mathrm{ZH}$ RILs were grown together with both parents at 11th March in the spring of 2017 and at 23rd June in the summer of 2017 at Zengcheng experimental station (N23 ${ }^{\circ} 5^{\prime}$, E113 $\left.34^{\prime}\right)$. The detailed climate data were in Table S15 (Additional file 1), including the average temperature and accumulated precipitation of each month. The soil type of the experimental station is sandy loam clay, and the watering regimes were well-watered. A randomized complete block planting with three replications was adopted. Plants were sown in single-row plots, and each plot contained 10 plants per row, with $0.5 \mathrm{~m}$ between the rows and $0.1 \mathrm{~m}$ between the plants. Field management followed normal soybean production practices for the area.

\section{Measurements of chlorophyll-content traits and data analyses}

According to the detailed description of the different growth stages of soybean by Hanway and Thompson, we chose three representative soybean reproductive growth stages for phenotypic data valuations: the beginning flowering growth stage (R1), the full pod growth stage (R4) and the full seed growth stage (R6) [65]. Due to the diverse growth rates of the RILs, the phenotypic data for the chlorophyll-content traits were collected across different periods. The detailed information for different soybean growth stages was displayed in Table S15 (Additional file 1). The testing and sampling targets were the five plants in the middle of each row.

\section{Soybean leaf SPAD testing determinations}

The soil plant analysis development (SPAD) chlorophyll meter non-destructively measures light transmittance of the leaf in the red and infrared wavelengths at 650 and $940 \mathrm{~nm}$, yielding a numerical output that indicates leaf greenness and chlorophyll concentration [5]. Assessing chlorophyll content in leaf with the SPAD chlorophyll meter is a quick, cheap and effective approach to gain the phenotypic data for soybean leaf chlorophyllcontents. In this study, the SPAD values were scored in the middle leaflets of fully expanded trifoliolate soybean leaves using the SPAD-502 Chlorophyll Meter (Konica Minolta, Japan). Five normal plants in the middle of each row were selected and measured SPAD values of the definite leaves thrice at the top, middle and bottom sites of the plants [30]. The mean testing values of plant different sites were set as the TSP, MSP and BSP, respectively. Moreover, the average SPAD values (ASP) were the means of TSP, MSP and BSP. And all the SPAD values were collected at 9 a.m.

\section{Soybean leaf pigment extractions and extracted-based chlorophyll evaluations}

In this study, we collected the fully developed middle leaflets of the 3rd node on the main stem counting down from the top for soybean leaf pigment extractions at 9 a.m. The leaf samples were from the five single plants of each row. Leaf samples, avoid the main leaf veins, were cut into small pieces and then were ground to crush in liquid nitrogen. About $0.3 \mathrm{~g}$ of every sample (Ws, the weight of the sample) were sent into a $10 \mathrm{~mL}$ centrifuge tube and added $9 \mathrm{~mL}$ pre-refrigerated extraction solvent (80\% v/v acetone). Samples were incubated at room temperature in the dark for two hours until the crush completely became white. During the incubating process, the centrifuge tubes were preferably shaken up several times to ensure the well-extracted chlorophylls. Then the tubes were centrifuged at $9000 \times \mathrm{g}$ for $10 \mathrm{~min}$ at $25^{\circ} \mathrm{C}$ (Centrifuge 5418R, Eppendorf, Hamburg Germany). After centrifuging, $1 \mathrm{~mL}$ supernatant liquor of each sample was transferred into an opaque glass vial and diluted the volume to $8 \mathrm{~mL}$ by $80 \% \mathrm{v} / \mathrm{v}$ acetone (diluted chlorophyll sample solution). The absorbance of the diluted samples was measured at $645 \mathrm{~nm}$ (A645) and $663 \mathrm{~nm}$ (A663) using a spectrophotometer (UV-1800 Spectrophotometer, SHIMADZU CORPORATION, Japan), respectively. The chlorophyll contents could be described as follows [52]:

$$
\begin{aligned}
& \text { Chl_A }(\mathrm{mg} / \mathrm{g})=\frac{(12.7 \times \mathrm{A} 663-2.69 \times \mathrm{A} 645) \times 8 \times 9}{1000 \times W_{s}} . \\
& \text { Chl_B }(\mathrm{mg} / \mathrm{g})=\frac{(22.9 \times \mathrm{A} 645-4.68 \times \mathrm{A} 663) \times 8 \times 9}{1000 \times W_{s}} .
\end{aligned}
$$

\section{Phenotypic data statistical analyses}

Chl_A/B values were obtained from the ratios of chlorophyll a to b. Frequency distribution graphs of chlorophyll-content traits (TSP, MSP, BSP, ASP, Chl_A, Chl_B and Chl_A/B) were depicted by Graphpad Prism 7.0 (http://www.graphpad.com/). Statistical analyses were manipulated with SPSS Statistics 19.0 (https:// www.ibm.com/products/spss-statistics) software. 


\section{Genetic map and QTL detection SNP genotyping}

Genome-wide SNP genotyping was performed at the Beijing Genome Institute (BGI) Tech, Shenzhen, China. According to the SNP genotyping method of Liu et al. [24], SOAP aligner (http://soap.genomics.org.cn/) was adopted to align the sequencing reads of parents and each RILs to Glyma.Wm82. a1. v1. 1 soybean reference genome from Phytozome (https://phytozome.jgi.doe.gov/ pz/portal.html) [66]. Using SAMtools (http://samtools. sourceforge.net/) software, the alignments were formatted and converted into realSFS input files for SNP calling and genotyping [67]. By using the sliding window approach with 15 SNPs per window, the genotype for each window and the exchange sites for each individual were determined. Finally, the genotypes of each individual were applied for generating bin information of the high-density genetic linkage map by MSTMap (http:// alumni.cs.ucr.edu/ yonghui/mstmap.html) [68]. The Mapchart (https://www.wur.nl/en/show/MapChart-2.32. htm) was used for depicting the genetic linkage maps with the map files from MSTMap [69]. And the genetic linkage map was constructed by the bin markers, which reduced the number of markers into one by integrating the SNPs in the same recombinant block. The bin marker number of each soybean chromosome was presented in Table S4 (Additional file 1). The maximum number of bin markers for each soybean chromosome should be no more than 350 .

\section{QTL detection}

Utilizing the well-constructed genetic linkage map and WinQTLCart2.5 (https://brcwebportal.cos.ncsu.edu/qtlcart/ WQTLCart.htm) software, we scanned the QTLs with the composite interval mapping (CIM) method [70, 71]. The logarithms of the odds (LOD) thresholds for QTL significance were determined by a permutation test (1000 replications) with a genome-wide at the $5 \%$ level of significance to justify the existence of QTLs. According to the tests, a LOD score of 2.5 was used as a minimum to announce the presence of a QTL in a particular genomic region [72]. Moreover, the location of a QTL was described according to its LOD peak location and the surrounding region with a 95\% confidence interval. QTL mapping results were comprehensively compared to SoyBase.

\section{QTL naming}

The detected QTLs were named according to Cui et al. as follows: initial ' $\mathrm{q}$ ' denotes 'QTL'; following with chlorophyll-related traits abbreviation letters; the next number is the soybean chromosomes on which the QTL is distributed [73]. Moreover, letters ' $a$ ' to 'c' represent the QTL was detected in the ZH RIL population at the R1, R4 and R6 growth stages in the spring of 2017 at
Zengcheng, respectively; letters ' $\mathrm{d}$ ' to ' $\mathrm{f}$ ' represent the QTL was detected in the ZH RIL population at the R1, R4 and R6 growth stages in the summer of 2017 at Zengcheng, respectively; if more than one QTL for a specific trait was dispersed along a certain chromosome, a serial number, viz. $-1,2$, etc., is used after the ' $a$ ' to ' $\mathrm{f}$ ' to describe their order.

\section{Gene ontology (GO) enrichment analyses and candidate gene predictions}

In the current study, the Glyma.Wm82. a1. v1. 1 gene model on SoyBase was applied for retrieving the genes that fall into the hereditary blocks of detected QTLs. The AgriGo toolkit v2.0 (http://systemsbiology.cau.edu. cn/agriGOv2) was utilized to perform gene ontology (GO) analyses for these genes [74]. Besides, the GO enrichment terms were filtered $(P<0.05$ and gene number over five in the selected GO term) and illustrated by TBtools [75]. Furthermore, we looked up these gene annotations on SoyBase (https://www.soybase.org/) and gene tissues expression information on Phytozome and SoyBase. Comprehensively considering the gene annotations and gene tissue expression levels, the candidate genes for chlorophyll-content traits were predicted.

\section{Candidate gene genomic locations, conserved domains and gene structure depictions}

The genomic positions of the candidate genes were stepwise displayed from the anchored bin markers on soybean chromosomes to the candidate genes in the bin markers. The bin markers and the candidate genes were displayed at the ratios based on the soybean genome physical locations. For conserved domains, protein sequences of candidate genes were obtained from Phytozome and set as the inputs to the SMART (http://smart. embl-heidelberg.de/\#opennewwindow) online analyzing tool. Gene structures were depicted by TBtools software by using the soybean genome GFF3 file [75]. The graphs were modified by Microsoft Office PowerPoint 2016 and Adobe Illustrator CC 2019.

\section{Supplementary information}

Supplementary information accompanies this paper at https://doi.org/10. 1186/s12864-020-07150-4.

\footnotetext{
Additional file 1: Table S1: The pairwise correlation coefficients between different chlorophyll-content traits in the ZH RILs across environments; Table S2: Correlation coefficients between different environments for leaf chlorophyll-content traits in the ZH RILs; Table S3: Number of SNPs in the bin markers; Table S4: Description of characteristics of 20 chromosomes in the ZH RIL population high-density genetic map; Table S5: Segregation distortions of 2639 bin markers among the ZH RIL population; Table S6: The 78 QTLS and 70 loci for leaf chlorophyll-content traits in the ZH RIL population across different environments; Table S7 Information of Soybase published leaf chlorophyll-content traits QTLs; Table S8: Comparisons of the detected chlorophyll-content QTLs with
} 
the previously published ones; Table S9: Five important chlorophyllcontent traits QTL hotspots are associated with several reported yieldrelated QTLS on SoyBase; Table S10: Genes in the hereditary intervals of the 13 major chlorophyll-content trait QTLs; Table S11: Genes in the hereditary intervals of the five important QTL hotspots; Table S12: Gene Ontology (GO) enrichment analysis of the genes in genetic blocks of the major QTLs and important QTL hotspots; Table S13: Filtered GO enrichment terms of the genes in genetic blocks of the major QTLs and important QTL hotspots; Table S14: Gene annotations from SoyBase; Table S15: Details of field trails, meteorological conditions and soybean growth stages used to determine the soybean leaf chlorophyll-content traits.

Additional file 2: Fig. S1: Distribution of the SNP loci throughout 20 soybean chromosomes in the ZH RIL population.

Additional file 3: Fig. S2: Schematic and distribution of bin markers on 20 soybean chromosomes in the ZH RIL population.

Additional file 4: Fig. S3: Visualization of the filtered GO enrichment terms

\section{Abbreviations}

Aldedh: Aldehyde dehydrogenase; ASP: Average SPAD value; BN: Branch number; bp: Base pair; BSP: Bottom leaves SPAD value; CDS: Coding sequence; Chl_A/B: Ratios of chlorophyll a to b; Chl_A: Chlorophyll a; Chl_B: Chlorophyll b; ChloroA_B-bind: Chlorophyll A-B binding; CIM: Composite interval mapping; CM: Centimorgan; CT: Chlorophyll-content traits; CV.: Cultivar; EP: Effective pod; GBS: Genotyping by sequencing; GO: Gene ontology; GWAS: Genome-wide association study; IP: Invalid pod; kb: Kilobyte; LOD: Logarithms of the odds; MAS: Marker-assisted selective; Mb: Megabyte; MSP: Middle leaves SPAD value; NAD: Nicotinamide adenine dinucleotide; NGS: Next-generation sequencing; NN: Nod number; PAP: Plastid-lipid associated protein; PH: Plant height; QTL: Quantitative trait locus; $R^{2}$ : Phenotypic variance; RAD-seq: Restriction site-associated DNA sequencing; RIL: Recombinant inbred line; SLAF-seq: Specific length amplified fragment sequencing; SNP: Single nucleotide polymorphism; SPAD: Soil plant analysis development; SSD: Single seed descent; SW: Seed weight; TSP: Top leaves SPAD value; UTR: Untranslated region; WGS: Whole-genome sequencing

\section{Acknowledgments}

Not applicable.

\section{Authors' contributions}

HN conceived the research and supervised the project. LW participated in experimental design, conducted field experiments, phenotypic data collections, data analyses, candidate gene predictions and prepared the draft. LW and HN wrote and revised the manuscript. BC participated in phenotypic data collections. LZF provided the target trait testing method. QJX was responsible for genotyping work and mapping the QTLS. All authors approved the final manuscript

\section{Funding}

This research was funded by supported by the Key-Areas Research and Development Program of Guangdong Province (2020B020220008), the National Key R\&D Program of China (2018YFD0201006), the China Agriculture Research System (CARS-04-PS09), the Guangdong Agricultural Research System (2019KJ136) and the Research Project of the State Key Laboratory of Agricultural and Biological Resources Protection and Utilization in Subtropics (4100M13024). The funding bodies had no role in study design, data collection, analysis and interpretation, decision to publish, or writing of the manuscript.

\section{Availability of data and materials}

The data sets supporting the results of this study are included in the manuscript. Soybean seeds are available from the Guangdong Subcenter of the National Center for Soybean Improvement, PR China.

\section{Ethics approval and consent to participate}

Not applicable.

\section{Consent for publication}

Not applicable.

\section{Competing interests}

The authors declare that they have no competing interests.

\section{Author details}

${ }^{1}$ The State Key Laboratory for Conservation and Utilization of Subtropical Agro-bioresources, South China Agricultural University, Guangzhou 510642, Guangdong, People's Republic of China. ${ }^{2}$ The Key Laboratory of Plant Molecular Breeding of Guangdong Province, College of Agriculture, South China Agricultural University, Guangzhou 510642, Guangdong, People's Republic of China. ${ }^{3}$ Guangdong Provincial Laboratory of Lingnan Modern Agricultural Science and Technology, South China Agricultural University, Guangzhou 510642, Guangdong, People's Republic of China. ${ }^{5}$ Soybean Research Institute, National Center for Soybean Improvement, Key Laboratory of Biology and Genetic Improvement of Soybean (General, Ministry of Agriculture), State Key Laboratory of Crop Genetics and Germplasm Enhancement, Jiangsu Collaborative Innovation Center for Modern Crop Production, College of Agriculture, Nanjing Agricultural University, Nanjing 210095, People's Republic of China. ${ }^{5}$ Beijing Genomics Institute (BGl) Education Center, University of Chinese Academy of Sciences, Shenzhen 518083, Guangdong, People's Republic of China.

Received: 1 June 2020 Accepted: 13 October 2020

Published online: 23 October 2020

\section{References}

1. Carter GA, Knapp AK. Leaf optical properties in higher plants: linking spectral characteristics to stress and chlorophyll concentration. Am J Bot. 2001;88(4):677-84.

2. Dhanapal AP, Ray JD, Singh SK, Hoyos-Villegas V, Smith JR, Purcell LC, Fritschi FB. Genome-wide association mapping of soybean chlorophyll traits based on canopy spectral reflectance and leaf extracts. BMC Plant Biol. 2016;16(1):174.

3. Chappelle EW, Kim MS, McMurtrey JE. Ratio analysis of reflectance spectra (RARS): an algorithm for the remote estimation of the concentrations of chlorophyll a, chlorophyll B, and carotenoids in soybean leaves. Remote Sens Environ. 1992;39(3):239-47.

4. Singh SK, Hoyos-Villegas V, Ray JD, Smith JR, Fritschi FB. Quantification of leaf pigments in soybean (Glycine max (L.) Merr.) based on wavelet decomposition of hyperspectral features. Field Crop Res. 2013;149:20-32.

5. Lombard K, O'Neill M, Mexal J, Ulery A, Onken B, Bettmann G, Heyduck R. Can soil plant analysis development values predict chlorophyll and total Fe in hybrid poplar? Agrofor Syst. 2010;78(1):1-11.

6. Hesketh JD, Ogren WL, Hageman ME, Peters DB. Correlations among leaf $\mathrm{CO}_{2}$-exchange rates, areas and enzyme activities among soybean cultivars. Photosynth Res. 1981;2(1):21-30.

7. Ma BL, Morrison MJ, Voldeng HD. Leaf greenness and photosynthetic rates in soybean. Crop Sci. 1995;35(5):1411-4.

8. Karikari B, Li SG, Bhat JA, Cao YC, Kong JJ, Yang JY, Gai JY, Zhao TJ. Genome-wide detection of major and epistatic effect QTLs for seed protein and oil content in soybean under multiple environments using high-density bin map. Int J Mol Sci. 2019;20(4):979.

9. Grant JR, Arantes AS, Liao X, Stothard P. In-depth annotation of SNPs arising from resequencing projects using NGS-SNP. Bioinformatics. 2011;27(16): 2300-1.

10. Hendre PS, Kamalakannan R, Rajkumar R, Varghese M. High-throughput targeted SNP discovery using next generation sequencing (NGS) in few selected candidate genes in Eucalyptus camaldulensis. BMC Proc. 2011; 5(7):017.

11. Delourme R, Falentin C, Fomeju BF, Boillot M, Lassalle G, André I, Duarte J, Gauthier V, Lucante N, Marty A, et al. High-density SNP-based genetic map development and linkage disequilibrium assessment in Brassica napusL. BMC Genomics. 2013;14(1):120.

12. $M a$ JQ, Huang $L$, Ma CL, Jin JQ, Li CF, Wang RK, Zheng HK, Yao MZ, Chen L. Large-scale SNP discovery and genotyping for constructing a high-density genetic map of tea plant using specific-locus amplified fragment sequencing (SLAF-seq). PLoS One. 2015;10(6):e0128798.

13. Chen JF, Huang QF, Gao DY, Wang JY, Lang YS, Liu TY, Li B, Bai ZT, Luis Goicoechea J, Liang CZ, et al. Whole-genome sequencing of Oryza brachyantha reveals mechanisms underlying Oryza genome evolution. Nat Commun. 2013;4(1):1595. 
14. Qi XP, Li MW, Xie M, Liu X, Ni M, Shao GH, Song C, Kay-Yuen Yim A, Tao Y, Wong $F L$, et al. Identification of a novel salt tolerance gene in wild soybean by whole-genome sequencing. Nat Commun. 2014;5(1):4340.

15. Elshire RJ, Glaubitz JC, Sun Q, Poland JA, Kawamoto K, Buckler ES, Mitchell SE. A robust, simple genotyping-by-sequencing (GBS) approach for high diversity species. PLoS One. 2011;6(5):e19379.

16. Sun XW, Liu DY, Zhang XF, Li WB, Liu H, Hong WG, Jiang CB, Guan N, Ma CX, Zeng HP, et al. SLAF-seq: an efficient method of large-scale de novo SNP discovery and genotyping using high-throughput sequencing. PLOS One. 2013;8(3):e58700.

17. Miller MR, Dunham JP, Amores A, Cresko WA, Johnson EA. Rapid and costeffective polymorphism identification and genotyping using restriction site associated DNA (RAD) markers. Genome Res. 2007;17(2):240-8.

18. Wang S, Meyer E, McKay JK, Matz MV. 2b-RAD: a simple and flexible method for genome-wide genotyping. Nat Methods. 2012;9(8):808-10.

19. Burridge AJ, Wilkinson PA, Winfield MO, Barker GLA, Allen AM, Coghill JA, Waterfall C, Edwards KJ. Conversion of array-based single nucleotide polymorphic markers for use in targeted genotyping by sequencing in hexaploid wheat (Triticum aestivum). Plant Biotechnol J. 2018;16(4):867-76.

20. Hu ZB, Olatoye MO, Marla S, Morris GP. An integrated genotyping-bysequencing polymorphism map for over 10,000 sorghum genotypes. Plant Genome. 2019;12(1):180044.

21. Jiang BZ, Cheng YB, Cai ZD, Li M, Jiang Z, Ma RR, Yuan YS, Xia QJ, Nian H. Fine mapping of a Phytophthora-resistance locus RpsGZ in soybean using genotyping-by-sequencing. BMC Genomics. 2020;21(1):280.

22. Trampe B, dos Santos IG, Frei UK, Ren JJ, Chen SJ, Lübberstedt T. QTL mapping of spontaneous haploid genome doubling using genotypingby-sequencing in maize (Zea mays L.). Theor Appl Genetics. 2020;133(1): 2131-40.

23. Yadav S, Sandhu N, Singh VK, Catolos M, Kumar A. Genotyping-bysequencing based QTL mapping for rice grain yield under reproductive stage drought stress tolerance. Sci Rep. 2019;9(1):14326.

24. Liu NX, Li M, Hu XB, Ma QB, Mu YH, Tan ZY, Xia QJ, Zhang GY, Nian H. Construction of high-density genetic map and QTL mapping of yieldrelated and two quality traits in soybean RILs population by RADsequencing. BMC Genomics. 2017;18(1):466.

25. Wang L, Cheng YB, Ma QB, Mu YH, Huang ZF, Xia QJ, Zhang GY, Nian H. QTL fine-mapping of soybean (Glycine max L.) leaf type associated traits in two RILs populations. BMC Genomics. 2019;20(1):260.

26. Wang $M$, Yan JB, Zhao JR, Song W, Zhang XB, Xiao YN, Zheng YL. Genomewide association study (GWAS) of resistance to head smut in maize. Plant Sci. 2012;196:125-31.

27. Funada M, Helms TC, Hammond JJ, Hossain K, Doetkott C. Single-seed descent, single-pod, and bulk sampling methods for soybean. Euphytica. 2013;192(2):217-26.

28. Fang C, Ma YM, Wu SW, Liu Z, Wang Z, Yang R, Hu GH, Zhou ZK, Yu H, Zhang $M$, et al. Genome-wide association studies dissect the genetic networks underlying agronomical traits in soybean. Genome Biol. 2017; 18(1):161.

29. Hu ZB, Zhang HR, Kan GZ, Ma DY, Zhang D, Shi GX, Hong DL, Zhang GZ, Yu DY. Determination of the genetic architecture of seed size and shape via linkage and association analysis in soybean (Glycine max L. Merr.). Genetica. 2013;141(4):247-54.

30. Li GJ, Li HN, Cheng LG, Zhang YM. QTL analysis for dynamic expression of chlorophyll content in soybean (Glycine max L. Merr.). Acta Agron Sin. 2010; 36(2):242-8.

31. Shi $X L$, Yan L, Yang CY, Yan WW, Moseley DO, Wang T, Liu BQ, Di R, Chen PY, Zhang MC. Identification of a major quantitative trait locus underlying salt tolerance in 'Jidou 12' soybean cultivar. BMC Res Notes. 2018;11(1):95.

32. Du WJ, Wang M, Fu SX, Yu DY. Mapping QTLs for seed yield and drought susceptibility index in soybean (Glycine max L.) across different environments. J Genet Genomics. 2009;36(12):721-31.

33. Guzman PS, Diers BW, Neece DJ, St. Martin SK, LeRoy AR, Grau CR, Hughes TJ, Nelson RL. QTL associated with yield in three backcross-derived populations of soybean. Crop Sci. 2007;47(1):111-22.

34. Han YP, Li DM, Zhu D, Li HY, Li XP, Teng WL, Li WB. QTL analysis of soybean seed weight across multi-genetic backgrounds and environments. Theor Appl Genet. 2012;125(4):671-83.

35. Hu ZB, Zhang D, Zhang GZ, Kan GZ, Hong DL, Yu DY. Association mapping of yield-related traits and SSR markers in wild soybean (Glycine soja Sieb. And Zucc.). Breed Sci. 2014;63(5):441-9.
36. Hyten DL, Pantalone VR, Sams CE, Saxton AM, Landau-Ellis D, Stefaniak TR, Schmidt ME. Seed quality QTL in a prominent soybean population. Theor Appl Genet. 2004;109(3):552-61.

37. Josie J, Alcivar A, Rainho J, Kassem MA. Genomic regions containing QTL for plant height, internodes length, and flower color in soybean [Glycine max (L.) Merr]. BIOS. 2007:78(4):119-26.

38. Mansur LM, Lark KG, Kross H, Oliveira A. Interval mapping of quantitative trait loci for reproductive, morphological, and seed traits of soybean (Glycine max L.). Theor Appl Genet. 1993:86(8):907-13.

39. Ning HL, Yuan JQ, Dong QZ, Li WB, Xue H, Wang YS, Tian Y, Li WX. Identification of QTLs related to the vertical distribution and seed-set of pod number in soybean [Glycine max (L.) Merri]. PLoS One. 2018;13(4):e0195830.

40. Panthee DR, Pantalone VR, West DR, Saxton AM, Sams CE. Quantitative trait loci for seed protein and oil concentration, and seed size in soybean. Crop Sci. 2005:45(5):2015-22.

41. Reinprecht Y, Poysa V, Yu K, Rajcan I, Ablett G, Pauls K. Seed and agronomic QTL in low linolenic acid, lipoxygenase-free soybean (Glycine max (L.) Merrill) germplasm. Genome. 2006;49:1510-27.

42. Sonah H, O'Donoughue L, Cober E, Rajcan I, Belzile F. Identification of loci governing eight agronomic traits using a GBS-GWAS approach and validation by QTL mapping in soya bean. Plant Biotechnol J. 2015;13(2):211-21.

43. Sun DS, Li WB, Zhang ZC, Chen QS, Ning HL, Qiu LJ, Sun GL. Quantitative trait loci analysis for the developmental behavior of soybean (Glycine max $\mathrm{L}$. Merr.). Theor Appl Genet. 2006;112(4):665-73.

44. Teng W, Han Y, Du Y, Sun D, Zhang Z, Qiu L, Sun G, Li W. QTL analyses of seed weight during the development of soybean (Glycine max L. Merr.). Heredity. 2009;102(4):372-80.

45. Wang $X Z$, Jiang GL, Green M, Scott RA, Song QJ, Hyten DL, Cregan PB. Identification and validation of quantitative trait loci for seed yield, oil and protein contents in two recombinant inbred line populations of soybean. Mol Gen Genomics. 2014;289(5):935-49.

46. Sims DA, Gamon JA. Relationships between leaf pigment content and spectral reflectance across a wide range of species, leaf structures and developmental stages. Remote Sens Environ. 2002:81(2):337-54.

47. Zhang Y, Huang JF, Wang FM, Blackburn GA, Zhang HK, Wang XZ, Wei CW, Zhang KY, Wei C. An extended prospect: advance in the leaf optical properties model separating total chlorophylls into chlorophyll a and b. Sci Rep. 2017;7(1):6429.

48. Orf JH, Chase K, Adler FR, Mansur LM, Lark KG. Genetics of soybean agronomic traits: II. Interactions between yield quantitative trait loci in soybean. Crop Sci. 1999;39(6):1652-7.

49. Xavier A, Hall B, Casteel S, Muir W, Rainey K. Using unsupervised learning techniques to assess interactions among complex traits in soybeans. Euphytica. 2017;213(8):200

50. Tian ZX, Wang XB, Lee R, Li YH, Specht JE, Nelson RL, McClean PE, Qiu LJ, Ma JX. Artificial selection for determinate growth habit in soybean. P Natl Acad Sci USA. 2010;107(19):8563-8.

51. Cui M, Jia B, Liu HH, Kan X, Zhang Y, Zhou RH, Li ZP, Yang L, Deng DX, Yin $\mathrm{ZT}$. Genetic mapping of the leaf number above the primary ear and its relationship with plant height and flowering time in maize. Front Plant Sci. 2017:8:1437

52. Porra RJ. The chequered history of the development and use of simultaneous equations for the accurate determination of chlorophylls a and b. Photosynth Res. 2002;73(1):149-56.

53. Takuno S, Terauchi R, Innan H. The power of QTL mapping with RILs. PLoS One. 2012;7(10):e46545.

54. Tanksley SD. Mapping polygenes. Annu Rev Genet. 1993;27(1):205-33.

55. Pease JB, Hahn MW. More accurate phylogenies inferred from lowrecombination regions in the presence of incomplete lineage sorting. Evolution. 2013;67(8):2376-84.

56. Cockram J, Mackay I. Genetic mapping populations for conducting high-resolution trait mapping in plants. Adv Biochem Eng Biotechnol. 2018;164:109-38.

57. Wang L, Ding XL, Gao YQ, Yang SP. Genome-wide identification and characterization of GRAS genes in soybean (Glycine max). BMC Plant Biol. 2020;20(1):415.

58. Jiang SK, Zhang XJ, XU ZJ, Chen WF. Comparison between QTLs for chlorophyll content and genes controlling chlorophyll biosynthesis and degradation in Japonica rice. Acta Agron Sin. 2010;36(3):376-84

59. Simkin AJ, Gaffé J, Alcaraz JP, Carde JP, Bramley PM, Fraser PD, Kuntz M. Fibrillin influence on plastid ultrastructure and pigment content in tomato fruit. Phytochemistry. 2007;68(11):1545-56. 
60. Klimmek F, Sjödin A, Noutsos C, Leister D, Jansson S. Abundantly and rarely expressed $L h c$ protein genes exhibit distinct regulation patterns in plants. Plant Physiol. 2006;140(3):793-804.

61. Andersson U, Heddad M, Adamska I. Light stress-induced one-helix protein of the chlorophyll a/b-binding family associated with photosystem I. Plant Physiol. 2003;132(2):811-20.

62. Sun XL, Yu QY, Tang LL, Ji W, Bai X, Cai H, Liu X-F, Ding XD, Zhu YM. GsSRK, a G-type lectin S-receptor-like serine/threonine protein kinase, is a positive regulator of plant tolerance to salt stress. J Plant Physiol. 2013;170(5):505-15.

63. Xu XZ, Guo RR, Cheng CX, Zhang HJ, Zhang YC, Wang XP. Overexpression of $A L D H 2 B 8$, an aldehyde dehydrogenase gene from grapevine, sustains Arabidopsis growth upon salt stress and protects plants against oxidative stress. Plant Cell Tiss Org. 2013;114(2):187-96.

64. Fritschi FB, Ray JD. Soybean leaf nitrogen, chlorophyll content, and chlorophyll a/b ratio. Photosynthetica. 2007:45(1):92-8.

65. Hanway JJ, Thompson HE. How a soybean plant develops. 1962. Available from https://lib.dr.iastate.edu/specialreports/62.

66. Li RQ, Li YR, Kristiansen K, Wang J. SOAP: short oligonucleotide alignment program. Bioinformatics. 2008;24(5):713-4.

67. Li H, Handsaker B, Wysoker A, Fennell T, Ruan J, Homer N, Marth G, Abecasis G, Durbin R. 1000 genome project data processing subgroup. The sequence alignment/map format and SAMtools. Bioinformatics. 2009;25(16):2078-9.

68. Huang XH, Feng Q, Qian Q, Zhao Q, Wang L, Wang AH, Guan JP, Fan DL, Weng QJ, Huang T, et al. High-throughput genotyping by whole-genome resequencing. Genome Res. 2009;19(6):1068-76.

69. Voorrips RE. MapChart: software for the graphical presentation of linkage maps and QTLs. J Hered. 2002;93(1):77-8.

70. Han YP, Teng WL, Yu KF, Poysa V, Anderson T, Qiu L, Lightfoot DA, Li WB. Mapping QTL tolerance to Phytophthora root rot in soybean using microsatellite and RAPD/SCAR derived markers. Euphytica. 2008;162(2):231-9.

71. Li HH, Ye GY, Wang JK. A modified algorithm for the improvement of composite interval mapping. Genetics. 2007;175(1):361-74.

72. Zeng ZB. Theoretical basis for separation of multiple linked gene effects in mapping quantitative trait loci. P Natl Acad Sci USA. 1993;90(23):10972.

73. Cui F, Zhao CH, Ding AM, Li J, Wang L, Li XF, Bao YG, Li JM, Wang HG. Construction of an integrative linkage map and QTL mapping of grain yield-related traits using three related wheat RIL populations. Theor Appl Genet. 2014;127(3):659-75.

74. Tian T, Liu Y, Yan HY, You Q, Yi X, Du Z, Xu WY, Su Z. agriGO v2.0: a GO analysis toolkit for the agricultural community, 2017 update. Nucleic Acids Res. 2017;45(W1):W122-9.

75. Chen CJ, Chen H, Zhang Y, Thomas HR, Frank MH, He YH, Xia R. TBtools: an integrative toolkit developed for interactive analyses of big biological data. Mol Plant. 2020;13(8):1194-202.

\section{Publisher's Note}

Springer Nature remains neutral with regard to jurisdictional claims in published maps and institutional affiliations.

Ready to submit your research? Choose BMC and benefit from:

- fast, convenient online submission

- thorough peer review by experienced researchers in your field

- rapid publication on acceptance

- support for research data, including large and complex data types

- gold Open Access which fosters wider collaboration and increased citations

- maximum visibility for your research: over $100 \mathrm{M}$ website views per year

At $\mathrm{BMC}$, research is always in progress.

Learn more biomedcentral.com/submissions 